\title{
A conceptual and methodological framework for measuring and modulating the attentional blink
}

\author{
Mary H. MacLean • Karen M. Arnell
}

Published online: 21 July 2012

(C) Psychonomic Society, Inc. 2012

\begin{abstract}
The attentional blink ( $\mathrm{AB})$ is a transient attention cost that is shown when report accuracy for a second target (T2) is reduced when $\mathrm{T} 2$ is presented within approximately $500 \mathrm{~ms}$ of a first target (T1). Thus, by definition an $\mathrm{AB}$ is only observed when $\mathrm{T} 2$ accuracy is reduced at short relative to long T1-T2 separations, and the magnitude of the $\mathrm{AB}$ is reflected in the change in $\mathrm{T} 2$ performance across target separations. However, the designs, analyses, and interpretations of several studies of the $\mathrm{AB}$ have suggested a lack of clear definitions about what constitutes a demonstration of the $\mathrm{AB}$, what constitutes a modulation of the $\mathrm{AB}$ across participant groups or manipulations, and how $\mathrm{AB}$ magnitude might best be represented accurately as a single value for a given individual. In this article, we discuss the important conceptual and methodological issues that should be considered when obtaining, analyzing, and interpreting $\mathrm{AB}$ data, and we discuss the pros and cons of various approaches while providing suggestions as to how best to validly represent the $\mathrm{AB}$ and its modulations.
\end{abstract}

Keywords Attentional blink - Divided attention and inattention $\cdot$ Psychometrics/testing

The attentional blink (AB) is a transient attention cost that is shown when report accuracy for a second target (T2) is reduced when T2 is presented within approximately $500 \mathrm{~ms}$ of a first target (T1; see Raymond, Shapiro, \& Arnell, 1992). The AB is a widely employed paradigm used to investigate the temporal limitations of attention. Various theoretical accounts of the $\mathrm{AB}$ exist, and multiple theoretical reviews are available to help investigators (see, e.g., the Attention, Perception, \& Psychophysics tutorial review by Dux \& Marois, 2009; Martens \& Wyble, 2010; Shapiro, Arnell, \& Raymond, 1997a). This

M. H. MacLean · K. M. Arnell ( $\bowtie)$

Department of Psychology, Brock University,

St. Catharines,

Ontario L2S 3A1, Canada

e-mail: karnell@brocku.ca tutorial is meant to complement those theoretical reviews with a review of the methodological issues relevant to the $\mathrm{AB}$. Specifically, this tutorial will discuss the methods necessary to observe, measure, and modulate the attentional blink, as well as providing recommendations of best practices to help investigators use the $\mathrm{AB}$ appropriately and effectively in their investigations. This tutorial is meant to be, as much as is possible, theoretically neutral, focusing on those methodological issues that are important regardless of the theoretical framework being used. These issues include:

- How to design an $\mathrm{AB}$ task to produce an $\mathrm{AB}$ reliably

- What counts as an $\mathrm{AB}$, and what does not

- The role of lag-1 sparing in capturing the $\mathrm{AB}$

- Whether baselines are necessary, and which ones to use

- What counts as a modulation of the AB

- How to estimate individual differences in the $\mathrm{AB}$

\section{The attentional blink}

The $\mathrm{AB}$ is an effect that captures the temporal costs of allocating attention selectively. The AB is typically observed using a rapid serial visual presentation (RSVP), although the stimuli need not be visual (e.g., Arnell \& Jolicœur, 1999; Duncan, Martens, \& Ward, 1997; Mondor, 1998; Shen \& Mondor, 2006; Tremblay, Vachon, \& Jones, 2005; Vachon \& Tremblay, 2008) or unimodal (Arnell \& Jenkins, 2004; Arnell \& Jolicœur, 1999; Arnell \& Larson, 2002; Jolicœur, 1999; Soto-Faraco et al., 2002), and the RSVP stream per se is not required, as the AB has also been observed by simply using two backward-masked targets (Duncan, Ward, \& Shapiro, 1994).

What is RSVP and how is it used to show an AB?

In RSVP, visual stimuli (e.g., letters, numbers, pictures, or words) are presented sequentially at a rate that is usually 
around 10 items per second, or around $100 \mathrm{~ms}$ per item, varying somewhat according to the stimuli that are used (see Fig. 1). In a typical AB task, two of the items are targetsthe first target (T1) and second target (T2) — and the rest are distractors (see Broadbent \& Broadbent, 1987, for the first dual-target RSVP study). Although some AB tasks have employed more than two targets (Di Lollo, Kawahara, Ghorashi, \& Enns, 2005; Dux, Asplund, \& Marois, 2008; Kawahara, Enns, \& Di Lollo, 2006a; Kawahara, Kumada, \& Di Lollo, 2006b; Olivers, van der Stigchel, \& Hulleman, 2007), typically only two targets are used, and no more than two targets are required for most purposes. An attentiondemanding task is assigned to each of the targets. The two types of tasks typically employed are identification (i.e., $n$ alternative forced choice) or detection (presence/absence) of the target items. The T1 and T2 tasks can be the same (e.g., "report the two red letters" or "report the two digits") or different, such that a task switch is required between $\mathrm{T} 1$ and T2 (e.g., "report the identity of the lone white letter and whether an X was present or absent"). Responses to the targets are typically made offline (i.e., unspeeded) at the end of the each trial, and target accuracy is the dependent variable of interest.

The proximity of the second target in the RSVP stream relative to the first, referred to as a lag, is manipulated. Lag can be expressed either as the relative position of $\mathrm{T} 2$ following $\mathrm{T} 1$, or as the time between the onsets of $\mathrm{T} 1$ and $\mathrm{T} 2$ - the stimulus onset asynchrony (SOA). For example, a lag of 1 typically indicates that $\mathrm{T} 2$ is the first item following $\mathrm{T} 1$, and this typically corresponds to an SOA of approximately $100 \mathrm{~ms}$; a lag of 2 indicates that there is one intervening distractor between the two targets, which typically corresponds to an SOA of approximately $200 \mathrm{~ms}$; and so forth. So, a typical AB task consists of two targets embedded in an RSVP stream, so that the position of T2 relative to T1, known as lag, varies. Target performance can then be analyzed as a function of that lag in order to determine whether the lag influences T2 performance.

The description above of a "typical" AB paradigm is meant to depict a situation that will reliably produce an $\mathrm{AB}$; this paradigm has been used so extensively that it is relatively easy to place the results in the context of the wider $\mathrm{AB}$ literature. This typical $\mathrm{AB}$ paradigm will satisfy the purposes of many investigators, and thus is recommended. However, there is evidence to suggest that many of the requirements of this typical $\mathrm{AB}$ paradigm are not necessary in order to observe an $\mathrm{AB}$ under all conditions. For example, it is possible to observe an $\mathrm{AB}$ without masking $\mathrm{T} 1$, so long as awareness of T1 still occurs and T2 is presented for a very brief duration (i.e., $\sim 58 \mathrm{~ms}$; Nieuwenstein, Potter, \& Theeuwes, 2009a; Nieuwenstein, Van der Burg, Theeuwes, Wyble, \& Potter, 2009b). Similarly, an AB has been observed using T2 accuracy, albeit minimally, when $\mathrm{T} 2$ is unmasked, so long as the T2 task is difficult enough to not reach ceiling, especially at longer lags (Jannati, Spalek, \& Di Lollo, 2011). It is also possible to
Fig. 1 Typical attentional blink (AB) paradigm

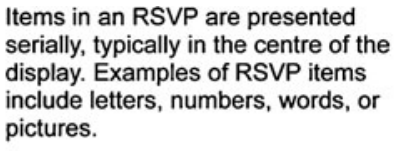

Items in an RSVP are presented serially, typically in the centre of the display. Examples of RSVP items include letters, numbers, words, or pictures.

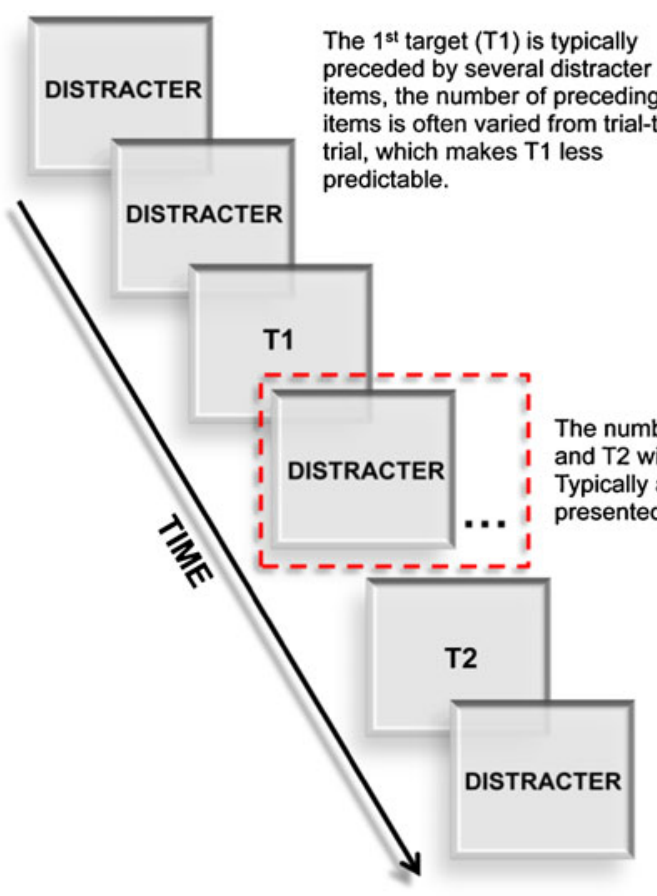

\section{Anatomy of an $\mathrm{AB}$ Paradigm using Rapid Serial Visual Presentation}

The $2^{\text {nd }}$ target (T2) should be followed by at least one distracter item, which acts as a mask, in order to reliably observe the $A B$ effect using accuracy or sensitivity measures of $\mathrm{T} 2$ performance. This is not a requirement if using reaction time to a speeded T2 task. 
use a speeded task for T1, or to have a masked and unspeeded $\mathrm{T} 1$ but to use response time as the dependent variable when $\mathrm{T} 2$ is speeded and unmasked (e.g., Jolicœur, 1998, 1999; Jolicœur \& Dell'Acqua, 1998). In the latter studies, an AB is indicated by an increased response time at short lags relative to long ones.

An alternative to the typical use of RSVP is the attentionaldwell-time, or skeletal $A B$, paradigm, in which only two spatially and temporally separated targets and their backward pattern masks are displayed (Ward, Duncan, \& Shapiro, 1996, Ward, Duncan, \& Shapiro, 1997). Individual AB performance using the dwell-time paradigm has been shown to be positively correlated with the AB from typical RSVP procedures (McLaughlin, Shore, \& Klein, 2001). However, electrophysiological evidence has demonstrated that the targets are processed differently in the skeletal paradigm than in the typical or "canonical" AB paradigm (Craston, Wyble, \& Bowman, 2006), and some have suggested that the spatial disparity between the two targets produces a spatial switch cost in addition to the dual-task attention costs manifest in the $\mathrm{AB}$. Certainly it is possible to argue that any $\mathrm{AB}$ paradigm in which some switch is required between $\mathrm{T} 1$ and $\mathrm{T} 2$, such as a task switch, modality switch, or spatial switch, will result in a combination of switch costs and the attentional costs relevant to the AB (Chun \& Potter, 2001; Potter, Chun, Banks, \& Muckenhoupt, 1998; Visser, Bischof, \& Di Lollo, 1999a, and investigators are advised to consider this when designing their AB paradigm. Importantly, there is evidence that spatial or multidimensional switches abolish lag-1 sparing (Visser et al. 1999a, Visser, Zuvic, Bischof, \& Di Lollo, 1999b), as does failure to mask T1 effectively (Martin \& Shapiro, 2008), and such procedures should thus be avoided by those wishing to observe lag-1 sparing.

In the original $\mathrm{AB}$ task from Raymond, Shapiro, and Arnell (1992)), T1 was the sole white letter presented among black letter distractor items, while T2 was the letter "X" presented at one of eight lags following $\mathrm{T} 1$ on half of the trials. In the experimental (dual-task) condition, participants were asked to report the identity of the white T1 letter and to report the presence or absence of the T2 letter "X." In the control (single-task) condition, both $\mathrm{T} 1$ and $\mathrm{T} 2$ were present, although $\mathrm{T} 1$ was to be ignored and participants only reported whether the $\mathrm{T} 2$ " $\mathrm{X}$ " was present or absent on each trial. Raymond et al. (1992) observed that in the dual-task condition, correct detection of the " $\mathrm{X}$ " was reduced at lags $2-5$, (corresponding to SOAs of $180-450 \mathrm{~ms}$ after T1), as compared to $\mathrm{T} 2$ performance at similar serial positions in the control condition. Detection of T2 was not impaired in the dual-task condition when $\mathrm{T} 2$ was the immediate post-T1 item (i.e., at lag 1), or at lags 6-8 (540-720 ms), as compared to $\mathrm{T} 2$ performance at similar serial positions in the control condition. Thus, the posttarget impairment is temporary, and it is this temporary deficit that characterizes the
AB. Therefore, the primary criterion for identifying the presence of an $\mathrm{AB}$ effect is evidence of a lag-dependent effect on T2 performance in which performance is lower at short target separations (i.e., within $500 \mathrm{~ms}$ ) relative to longer target separations (see Fig. 2).

\section{The function's slope defines the $A B$, not the height}

The AB has been widely employed, for diverse purposes, as an index of temporal attentional limitations. Specific criteria define the $A B$ effect, and other specific criteria demonstrate modulations of the $\mathrm{AB}$ effect and can be used to estimate individual differences in the magnitude of the $A B$ effect. The purpose of this tutorial is to discuss those criteria and to examine the pros and cons of different approaches to capturing the $\mathrm{AB}$ and modulations of the $\mathrm{AB}$.

An idea of the necessity of a guide for the use and investigation of the $\mathrm{AB}$ was inspired by the surprisingly widespread misinterpretation of what the $\mathrm{AB}$ effect is, how it is measured, and what constitutes a modulation of the $A B$, which is apparent in the literature reviewed below. The $A B$ is represented by a function that describes how the temporal lag between two targets influences performance for the second target. In other words, T2 performance changes as the lag changes, demonstrating that the temporal distance between the two targets is relevant to performance for $\mathrm{T} 2$. To measure change in performance according to some continuous variable is not unusual among cognitive measures. Various other paradigms are defined by a similar function.

For example, in a mental rotation paradigm, the primary measure of interest is the speed of rotation, which is shown by

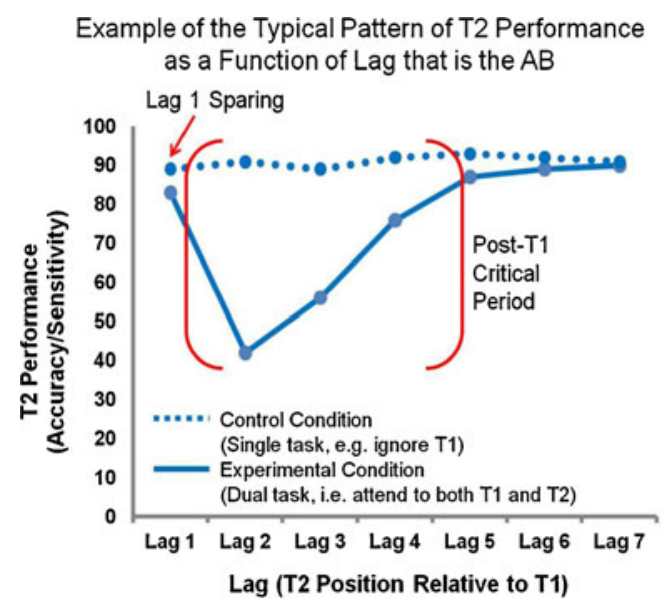

Fig. 2 The $\mathrm{AB}$ effect is evident, as $\mathrm{T} 2$ performance is impaired temporarily during a "critical" period following T1, corresponding to lags $2-5$ in this example, in the dual-task condition as compared to the single-task condition. T2 performance is seen to increase with lag, and this lag-dependent effect on $\mathrm{T} 2$ performance is the $\mathrm{AB}$ effect. Note that this and all subsequent figures are schematics in which no actual data are represented 
how response times change as a function of the degree of rotation, presumably as the object is being mentally rotated continuously along its axes (Shepard \& Cooper, 1982; Shepard $\&$ Metzler, 1971). Similarly, in visual search the primary measure of interest is response time as a function of the number of items in the search array, as this indicates the efficiency of the search (Treisman \& Gelade, 1980; Wolfe, 1998b). In both cases, the measure of interest is the change in performance as a function of some linearly increasing variable (i.e., the slope of the function). In the visual search paradigm, when response time increases as a function of the number of items in the search array, the slope of this function can differ according to the nature of the target amongst the distractors. For example, response time increases as the number of items in the array increases for most searches, but the slope of the function is much steeper when, for example, a green circle target is presented amongst green squares and red circles than when the same green circle target is presented amongst red squares, indicating less efficient search (Treisman \& Gelade, 1980). If researchers want to estimate the efficiency of search, they do not take the average of the response times across a given target condition (i.e., the height of the line), but rather the slope, showing the time cost per item for a given condition. It appears that the importance of slope as a measure of visual search performance is clear in the visual search literature, which is to say that while there may be controversy over the meaning of the slope, there is no question that the slope is the effect of interest, not the average response time, nor the intercept (for a review, see Wolfe, 1998a).

However, the AB, which is the function of $\mathrm{T} 2$ performance over temporal lag, appears to suffer from a misinterpretation involving the distinction between the slope and the height of a function. Specifically, the lag-dependent T2 accuracy function that is the AB is often treated interchangeably with the height of the function (i.e., mean T2 performance across lags). This would be the same as averaging response times across set sizes to get a measure of search efficiency in the visual search paradigm. Estimating the AB using overall T2 accuracy confounds the crucial aspect of the function of interest - the effect of the increasing temporal lag between two targets on target performance-with overall T2 performance ability, which evidence suggests are dissociable (Arnell, Howe, Joanisse, \& Klein, 2006; Arnell, Stokes, MacLean, \& Gicante, 2010; Colzato, Spapé, Pannebakker, \& Hommel, 2007). For example, if Participant A has $20 \% \mathrm{~T} 2$ accuracy at lag 3 and $80 \% \mathrm{~T} 2$ accuracy at lag 8 , he or she has $50 \% \mathrm{~T} 2$ accuracy overall and a very large lag-dependent difference in T2 accuracy (60\%, if the AB is measured as a simple subtraction of lag 8 - lag 3 T2 accuracy). If Participant $\mathrm{B}$ has $50 \% \mathrm{~T} 2$ accuracy at lag 3 and $50 \% \mathrm{~T} 2$ accuracy at lag 8 , then he or she too has $50 \% \mathrm{~T} 2$ accuracy overall, yet there is no lag-dependent $\mathrm{T} 2$ accuracy impairment that reflects the AB. Thus, a measure that represents the slope of the function correctly shows that the two participants have dramatically different AB magnitudes, whereas erroneously using overall T2 accuracy would suggest equal ABs for the two participants. Despite the simplicity of this illustration, the $\mathrm{AB}$ literature contains several examples of articles in which the $\mathrm{AB}$ is defined as overall T2 accuracy, or in which the AB is defined or interpreted in a manner that confounds T2 accuracy per se with the change in T2 accuracy across lags (e.g., Armstrong \& Munoz, 2003; Buchholz \& Davies, 2007; Cheung, Chen, Chen, Woo, \& Yee, 2002; Cooper, Humphreys, Hulleman, Praamstra, \& Georgeson, 2004; Facoetti, Ruffino, Peru, Paganoni, \& Chelazzi, 2008; Hari, Vata, \& Uutela, 1999; Klein, Arend, Beauducel, \& Shapiro, 2011; Lacroix et al., 2005; Lum, Conti-Ramsden, \& Lindell, 2007; Mason, Humphreys, \& Kent, 2005; Visser, Boden, \& Giaschi, 2004; Wynn, Breitmeyer, Nuechterlein, \& Green, 2006).

We are unsure why the AB is subject to this misinterpretation while other paradigms, such as visual search or mental rotation, are not. Regardless, this confusion has rather critical implications when attempting to observe, quantify, and modulate the $\mathrm{AB}$ effect. This discussion is meant to aid researchers who wish to use the $\mathrm{AB}$ paradigm to avoid misinterpretation, as well as to provide them with a better understanding of how the paradigm can best be used for their purposes.

\section{How do you know if you have an AB?}

Lag-1 sparing

Raymond et al. (1992) identified the critical period for the posttarget impairment of $\mathrm{T} 2$ performance as starting at $180 \mathrm{~ms}$, when T2 was presented as the second item following T1. When T2 was presented as the first item following T1, at lag 1, detection accuracy was not impaired relative to the control condition, and T2 performance decreased from lag 1 to lag 2. This is referred to as lag-1 sparing, although it is not always observed (Dell'Acqua, Jolicœur, Pascali, \& Pluchino, 2007; Visser et al. 1999a, b). The presence of lag-1 sparing has been influential in the development of theoretical models of the $\mathrm{AB}$, as its presences suggests that the item after T1 may have some role in the initiation of the $\mathrm{AB}$ (e.g., as in the boost-and-bounce model, Olivers \& Meeter, 2008; or the eSTST model, Bowman \& Wyble, 2007; Raymond et al., 1992). Furthermore, the absence of lag-1 sparing is sometimes taken as an indication that switch costs may be present in the AB (Visser et al. 1999a, b). Despite the fact that lag-1 sparing is intriguing and has implications for theoretical models of the $\mathrm{AB}$, the presence of lag-1 sparing is not necessary to indicate the presence of an AB. Lag-1 sparing reflects a unique set of circumstances that preserves $\mathrm{T} 2$ from the posttarget impairment that characterizes the AB (Akyürek \& Hommel, 2005; 
Hommel \& Akyürek, 2005; Kessler et al., 2005; Martin \& Shapiro, 2008; Visser, Davis, \& Ohan, 2009; Visser, Bischof, \& Di Lollo, 1999a, Visser et al. 1999b). There is also evidence that lag-1 sparing and the $\mathrm{AB}$ are dissociable (Livesey \& Harris, 2011).

Because lag-1 sparing is neither a necessary nor a sufficient condition attribute of the $\mathrm{AB}$, it is inappropriate to interpret the decrement in $\mathrm{T} 2$ performance from lag 1 to subsequent lags as indicative of an $\mathrm{AB}$ effect, as some authors have done (Munafò, Johnstone, \& Mackintosh, 2005; Vermeulen, Godefroid, \& Mermillod, 2009). In one such case, T2 performance was observed to decrease from lag 1 to lag 2 , which was correctly identified as lag-1 sparing, but $\mathrm{T} 2$ performance did not then increase from lag 2 to their longest lag, lag 5 (Munafò et al., 2005). Thus, an $A B$ effect was not observed, and the decrement in T2 performance from lag 1 to lag 2-lag-1 sparing - is not an equivalent substitute for such an effect (see Fig. 3).

\section{Choice of lags}

Since a lag-dependent effect on T2 performance is the primary indicator of the $\mathrm{AB}$ effect, any paradigm meant to capture the $\mathrm{AB}$ effect must contain more than one lag. It is also necessary that one of those lags be situated inside the critical period following $\mathrm{T} 1$ in which $\mathrm{T} 2$ performance deficits have been observed, while, ideally, the other should be situated outside of the critical period, where proximity to $\mathrm{T} 1$ no longer impairs T2 performance. It is obvious that without situating T2 at, at least, one shorter lag within the critical period it would not be possible to observe the posttarget impairment of T2 performance. What is, perhaps, less obvious is that without another, longer lag it will not be possible to observe the lag-dependent effect on T2 performance. For example, some investigations have designed an $\mathrm{AB}$ task with only one lag in the critical period following T1 (De

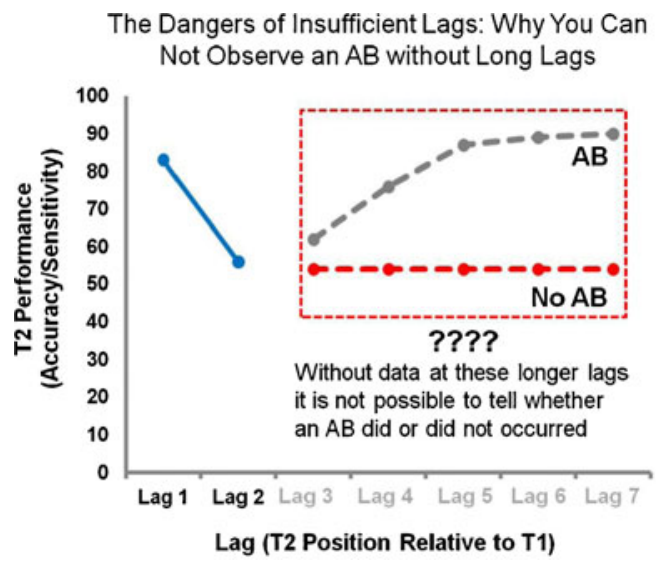

Fig. 3 In this example, T2 performance data have been obtained only at shorter lags (lag 1 and lag 2). Without the data at longer lags, is it not possible to observe whether or not the temporary posttarget impairment that is the $\mathrm{AB}$ has occurred
Martino, Kalisch, Rees, \& Dolan, 2009; Trippe, Hewig, Heydel, Hecht, \& Miltner, 2007). In both of these studies, the authors indicated that their results concerned the $\mathrm{AB}$ effect, and in one case the difference between $\mathrm{T} 1$ and $\mathrm{T} 2$ performance at a single lag was interpreted by the authors as a robust AB effect (De Martino et al., 2009). However, because there was only one lag, $\mathrm{T} 2$ performance could not be examined as a function of lag. Under these conditions, the $\mathrm{AB}$ and overall $\mathrm{T} 2$ accuracy were completely confounded. For example, if the group mean had $60 \%$ accuracy at lag 3 , but there was only lag 3 , it is possible that $\mathrm{T} 2$ accuracy would also equal $60 \%$ at a longer lag outside the $\mathrm{AB}$ interval. Without observing $\mathrm{T} 2$ performance as a function of lag, it cannot be determined whether lag influenced T2 performance, and thus, the required temporal pattern of the $\mathrm{AB}$ effect cannot be observed (see Fig. 3). It is possible that the costs associated with these particular investigations, especially in the case of the fMRI study (De Martino et al., 2009), demanded that the $A B$ task be as efficient as possible. However, without at least two lags, it is impossible to be sure whether the $\mathrm{AB}$ effect is present.

In summary, to determine whether or not the $\mathrm{AB}$ effect is present, $\mathrm{T} 2$ performance must be examined at, at least, two lags: one within the period of the temporary posttarget impairment (e.g., lag 2) and one after the posttarget impairment is expected to have passed (e.g., lag 7).

\section{Choice of baseline for estimating the $\mathrm{AB}$}

It was the comparison to performance in a control condition, in which $\mathrm{T} 1$ was to be ignored, that allowed Raymond et al. (1992) to attribute the AB effect to a posttarget impairment. The control condition showed that the lag relative to $\mathrm{T} 1$ was what affected T2 performance, and not simply the serial position of T2 in the RSVP or a forward-masking effect of the lone white letter (T1). It also allowed the researchers to identify the critical period during which the posttarget impairment was present (180-450 ms), and when it was absent (540-720 ms), as defined by a significant difference between $\mathrm{T} 2$ performance in the single- and dual-task conditions. While it is often a nice addition, however, the control condition is not necessary to capture the lag-dependent effect on $\mathrm{T} 2$ performance that is the AB. In some cases, a control condition would be a hindrance or unfeasible. The inclusion of a control condition requires that participants complete twice the number of trials, increasing the burden on the participant and the cost to the investigator. The inclusion of a control condition is also not practical when the T1 and $\mathrm{T} 2$ tasks are identical, as the first target, regardless of instructions to ignore it, is subject to contingent capture (Folk, Leber, \& Egeth, 2008). For example, if the T1 and T2 tasks were to identify the red letters from among black distractors, because both targets are defined by the 
same feature (i.e., redness), both targets would capture attention despite instructions to ignore the first red letter (T1). So, experimental requirements may make the inclusion of a control condition impractical, and so long as $\mathrm{T} 2$ performance can be examined as a function of lag (i.e., T2 performance at more than one lag), the presence of an $\mathrm{AB}$ effect can be determined.

Can you use the lag-dependent effect alone to estimate the $\mathrm{AB}$ ?

It has been argued that quantifying the AB using the lagdependent effect on T2 performance alone (i.e., the increase in T2 performance from shorter to longer lags) may underestimate the AB effect (Raymond, Shapiro, \& Arnell, 1995; Shore, McLaughlin, \& Klein, 2001) — specifically, that it is possible that, for some individuals at least, T2 performance at long lags thought to be outside the critical period (i.e., $>500 \mathrm{~ms}$ ) is still affected by the posttarget impairment (i.e., T2 performance at longer lags is not assuredly asymptotic; see Fig. 4). This is possible, and certainly without the control condition it is difficult to ascertain whether T2 performance at longer lags is no longer affected by the posttarget impairment. However, in several investigations that have employed a T1-absent or T1-ignore control condition, T2 performance at lags of 6 (i.e., T2 is the 6th item following $\mathrm{T} 1$, or $\sim 600 \mathrm{~ms}$ ) and longer were never observed to differ significantly in performance, as compared to when T2 was presented in the same position in the control condition (Arnell \& Jolicœur, 1999; Chua, 2005; Jolicœur, 1998; Maki \& Padmanabhan, 1994; Raymond, 2003; Raymond et al., 1992, 1995; Shapiro, Caldwell, \& Sorensen, 1997b; Shapiro, Raymond, \& Arnell, 1994; Stein, Zwickel, Ritter, Kitzmantel, \& Schneider, 2009). However, some groups

Influence of Asymptotic vs. Non-Asymptotic Long Lag T2 Performance on the AB

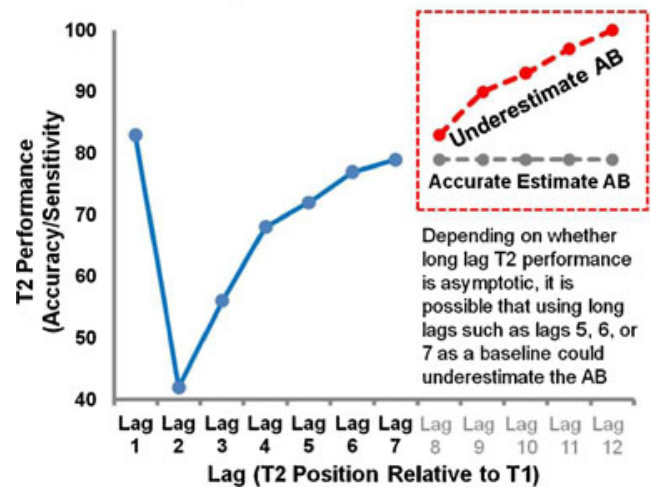

Fig. 4 The assumption that must be met when using the lag-dependent effect on $\mathrm{T} 2$ performance to quantify the $\mathrm{AB}$ is that performance at the longest lag has reached asymptote. If not, the function will underestimate the size of the $\mathrm{AB}$ effect. This example shows two possible patterns of T2 performance beyond lag 7, in one of which T2 performance continues to increase (red), indicating that T2 performance was not asymptotic at the longer lags with perceptual or cognitive impairment may demonstrate a posttarget impairment, as determined by comparison to a control condition, that extends beyond lag 6 , such as individuals with spatial neglect, who demonstrated a posttarget impairment that extended beyond 1,200 ms (Husain, Shapiro, Martin, \& Kennard, 1997).

One possible solution, to ensure that T2 performance has recovered from $\mathrm{T} 1$ processing, is to use excessively long lags as the baseline (i.e., $>1,000 \mathrm{~ms}$ ), as has been employed in a few studies (Cheung et al., 2002; Hari, Vata, Uutela, 1999; Visser et al., 2004). In such cases, however, it would be necessary to examine performance at these very long lags that one intends to use as a baseline in order to ensure that $\mathrm{T} 2$ performance at these lags is asymptotic, as intended. It is conceivable that other limits on attention-for example, fluctuations in vigilance - could impair T2 performance at excessively long lags. For example, in a case in which T2 is either present or absent, individuals may terminate their search for T2 near the end of the RSVP stream, feeling that T2 was either absent or was missed, before $\mathrm{T} 2$ is presented. The premature termination of search for $\mathrm{T} 2$ would create another lag effect in which $\mathrm{T} 2$ performance declines again after the initial recovery from the $\mathrm{AB}$ effect. In this scenario, $\mathrm{T} 2$ performance at the longer lags would not make an appropriate baseline to capture the $\mathrm{AB}$ effect, as it would be confounded by a different lagdependent effect. Using such excessively long lags may also not be practical for some research designs.

\section{Additional baselines for estimating the AB}

Where there are concerns that the lag-dependent effect on T2 performance is insufficient to capture the $\mathrm{AB}$ (i.e., that it will underestimate the magnitude of the effect), alternative baselines have been used. One such baseline is performance at ceiling (i.e., $100 \%$ ). However, using performance at ceiling as a baseline for the posttarget deficit would be confounded with other effects on T2 performance. As McLaughlin et al. (2001) pointed out, target performance is almost never at ceiling, even when it is not subject to dual-task impairments (see Fig. 5). Therefore, ceiling performance is an unrealistic baseline, as it would tend to overestimate the size of the $A B$ effect and to confound AB magnitude with overall T2 accuracy. This is especially problematic given that recent individualdifference studies of the $\mathrm{AB}$ have shown that different factors predict individual differences in overall $\mathrm{T} 2$ accuracy and $\mathrm{AB}$ magnitude (e.g., Arnell, Howe, Joanisse, \& Klein, 2006; Arnell et al., 2010; Arnell \& Stubitz, 2010; Colzato et al., 2007). Despite these problems, various investigations of the $\mathrm{AB}$ have used ceiling performance as a baseline for the purpose of capturing the AB (Grandison, Ghirardelli, \& Egeth, 1997; Raymond et al., 1995; Shapiro et al., 1994). However, because it is both unrealistic to treat ceiling as reflective of actual asymptotic performance, and because it fails to account 


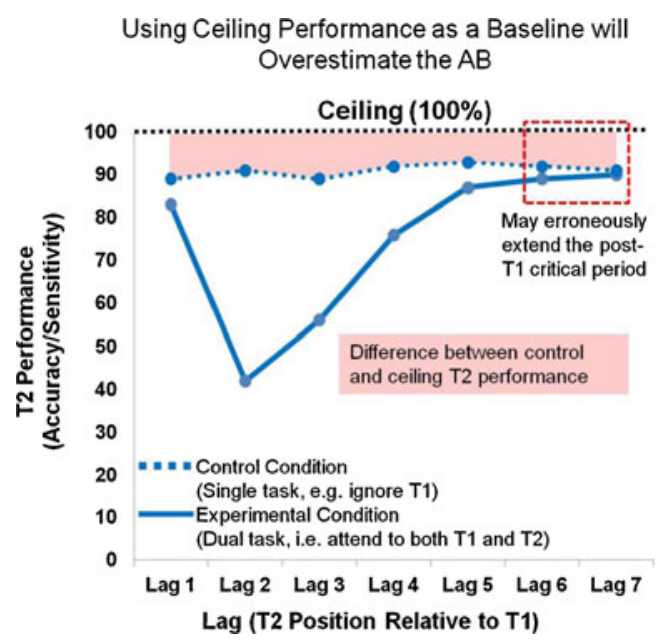

Fig. 5 In this example, it is apparent that using ceiling as the baseline in lieu of $\mathrm{T} 2$ performance in the control condition would overestimate the size of the $\mathrm{AB}$ effect, as $\mathrm{T} 2$ performance in the control condition is well below ceiling at all lags. In this case, for example, using ceiling performance as the baseline may yield significant differences at longer lags at which T2 performance is at asymptote and the posttarget impairment is absent

for additional confounding sources of impairment to overall target performance, ceiling is problematic as a baseline to capture the $\mathrm{AB}$ effect.

T1 performance has also been used as a baseline (Chua, 2005; McLaughlin et al., 2001; Shore et al., 2001). Shore et al. suggested that using $\mathrm{T} 1$ performance as a baseline avoids the issue of any posttarget influence, and thus will not misestimate the $\mathrm{AB}$. This, of course, rests on the assumption that $\mathrm{T} 1$ performance does actually resemble what performance in a control condition would be (see Fig. 6). There are three reasons to expect that $\mathrm{T} 1$ performance might not meet this assumption. One reason is that the $\mathrm{T} 1$ task often, although not always, differs from the T2 task. Apart from the issue of task switching (see Chun \& Potter, 2001), using T1 performance as a baseline for T2 performance when the tasks for the two targets differ means that one is comparing performance on two nonequivalent tasks. Despite that fact, this has been done in published $\mathrm{AB}$ studies (e.g., De Martino et al., 2009). This issue, of course, is easily remedied by using the same task for both $\mathrm{T} 1$ and $\mathrm{T} 2$, as was the case in the AB task used by Shore et al. when they suggested using T1 as a baseline. Using the same task for T1 and T2, however, does not address the issues that the serial position of $\mathrm{T} 1$ is often invariable, presented at the same position in the RSVP stream for every trial, and of lag-dependent effects on T1.

The control condition employed by Raymond et al. (1992) was particularly appropriate for capturing the $\mathrm{AB}$ effect, because it accounted for any possible influence of serial position in the RSVP stream on T2 performance, which would have been common to $\mathrm{T} 2$ in both the control and experimental conditions. Using $\mathrm{T} 1$ performance as a baseline fails to account for this issue, as $\mathrm{T} 1$ is often presented at a smaller range of earlier serial positions, relative to $\mathrm{T} 2$. If the appearance of $\mathrm{T} 1$ is
The Level of T1 Performance will Determine Whether it is an Accurate Baseline to Estimate the $A B$

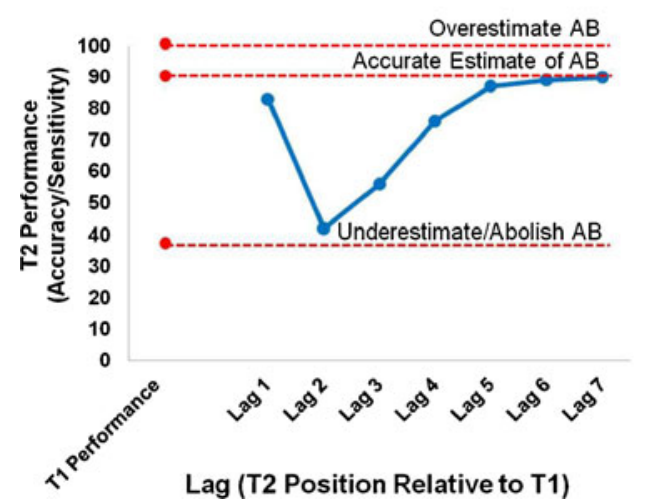

Fig. 6 It is possible to use T1 as a baseline to accurately estimate the $\mathrm{AB}$, should the various assumptions discussed here be met, depending on the level of $\mathrm{T} 1$ performance. If $\mathrm{T} 1$ performance is too high, it is likely to overestimate the $\mathrm{AB}$, just as ceiling performance will; if it is too low, it may abolish the $\mathrm{AB}$ entirely. However, if $\mathrm{T} 1$ performance is at a level similar to what could be expected for $\mathrm{T} 2$ performance in a control condition, it can be used effectively to estimate the $\mathrm{AB}$

more predictable and earlier in the stream, and so subject to possible anticipatory and primacy effects, $\mathrm{T} 1$ performance may be higher than $\mathrm{T} 2$ performance would be in a control condition, where T2 is both more unpredictable and presented later in the stream. So, the use of T1 performance, in this case, would overestimate the size of the $\mathrm{AB}$ effect (see Fig. 6).

In $\mathrm{AB}$ studies, $\mathrm{T} 2$ bears the brunt of the observed dual-task cost. However, it is often observed that $\mathrm{T} 1$ performance is also influenced by proximity to $\mathrm{T} 2$, in that there is fairly often a small lag effect on $\mathrm{T} 1$ performance. The typical pattern of this effect is such that $\mathrm{T} 1$ performance increases as lag increases. Although some of this effect can be attributed to switch errors when $\mathrm{T} 2$ is presented immediately following $\mathrm{T} 1$ (i.e., T2 is identified as $\mathrm{T} 1$, and vice versa), the impairment regularly extends to later lags as well ${ }^{1}$ and can be found even when T1 and $\mathrm{T} 2$ do not share the same response set. To the degree that $\mathrm{T} 1$ performance is impaired at short lags, use of overall $\mathrm{T} 1$ performance as a baseline would underestimate the $A B$ effect. Of course, it is possible to examine $\mathrm{T} 1$ performance posthoc and determine whether $\mathrm{T} 1$ performance was influenced by lag. In the case that $\mathrm{T} 1$ performance was affected by lag, it might suffice to only use T1 performance on trials in which T2 was presented at longer lags, although, just as there is uncertainty that $\mathrm{T} 2$ performance is asymptotic at longer lags, there is similar uncertainty that $\mathrm{T} 1$ performance is asymptotic even at longer lags.

\footnotetext{
${ }^{1}$ See Buchholz \& Davies, 2007; Facoetti et al., 2008; Ferlazzo, Lucido, Di Nocera, Fagioli, \& Sdoia, 2007; Ho, Mason, \& Spence, 2007; Kihara et al., 2007; Lum et al., 2007; McLaughlin et al., 2001; McLean, Castles, Coltheart, \& Stuart, 2010; McLean, Stuart, Visser, \& Castles, 2009; Olivers \& Nieuwenhuis, 2005, 2006; Raymond \& O’Brian, 2009; Raymond et al., 1992; Seiffert \& Di Lollo, 1997; Visser et al., 2004; Visser \& Ohan, 2007.
} 
In conclusion, various baselines can be used to capture the $\mathrm{AB}$ effect. The original control condition used by Raymond et al. (1992) - that is, T2 performance when T1 is present but ignored - is the least problematic, as the parameters of $\mathrm{T} 2$ in the control condition only differ from those of $\mathrm{T} 2$ in the experimental condition by one factor: whether or not a previous target was attended to. As the $\mathrm{AB}$ is, by definition, a posttarget deficit, the control condition used by Raymond et al. (1992)) allows for the cleanest approach to capturing the AB effect. However, it is also possible that the ignore-T1 condition, by requiring the suppression of processing the T1 stimulus, increases demands on those limited-capacity resources relevant to the $\mathrm{AB}$, so even the ignore-T1 baseline has its drawbacks. For various reasons, a researcher may choose not to include such a control condition, and in these cases there are alternative baselines to consider. The alternative baselines that have been used previously include ceiling performance $(100 \%)$ and T1 performance. Ceiling performance is an unrealistic representation of asymptotic target performance, leading to an overestimation of the $\mathrm{AB}$ effect, and it confounds the $\mathrm{AB}$ effect with the dissociable measure of overall T2 performance ability. Using overall T1 performance or long-lag T2 performance is preferrable, assuming that the same task is used for $\mathrm{T} 1$ and $\mathrm{T} 2$, and that T1 accuracy approximates long-lag T2 accuracy, but there is no assurance that these represent asymptotic levels of performance. Regardless of what baseline is employed to define the $\mathrm{AB}$ effect, it is important for any investigation that purports to examine the $\mathrm{AB}$ that the paradigm capture the lag-dependent effect on $\mathrm{T} 2$ performance. This remains the primary criterion that defines the $\mathrm{AB}$.

\section{Capturing modulations of the $A B$ effect}

Beyond simply capturing the $\mathrm{AB}$ effect, investigators often examine modulations of the $\mathrm{AB}$ effect via experimental manipulations or group differences. It is possible for $\mathrm{T} 2$ performance in an $\mathrm{AB}$ task to be modulated according to various dimensions (Cousineau, Charbonneau, \& Jolicœur, 2006). Of those dimensions that Cousineau et al. used to describe the curve of the AB effect, they identified the "amplitude," or the difference between asymptotic T2 performance at longer lags and the deepest depression in T2 performance at short lags, as capturing the severity of the post-T1 impairment that is the AB effect. Not all modulations of T2 performance indicate a modulation of the AB effect (McLean, Castles, Coltheart, \& Stuart, 2010). Since the primary criterion that defines the $A B$ is a lag-dependent effect of $\mathrm{T} 2$ performance, in order to modulate the $\mathrm{AB}$, the lag-dependent effect of $\mathrm{T} 2$ performance must be modulated. Modulations of the lag-dependent effect on T2 performance can be reflected in changes in the duration of the AB (such that the length of the period before $\mathrm{T} 2$ performance recovers to asymptotic levels increases or decreases) and/or in the severity or depth of the AB (such that the difference in T2 performance between short and long lags is increased or decreased). Changes in the depth and/or duration of the $\mathrm{AB}$ would be indicated by an interaction of the experimental condition or group with the lag effect on T2 performance, such that the particular temporal pattern of the lag-dependent effect differs between conditions or groups. Thus, the primary criterion required to capture the modulation of the $\mathrm{AB}$ effect is an interaction of the experimental condition or group with lag, typically captured in a two-factor ANOVA.

In many cases in which authors have claimed to demonstrate modulations of the $\mathrm{AB}$ effect, however, the requisite interaction with the lag-dependent effect was absent. For example, multiple investigations of group differences in the $\mathrm{AB}$ effect based on reading ability (i.e., dyslexia or specific language impairment) have claimed that the $\mathrm{AB}$ effect was greater - specifically, that the posttarget impairment of T2 performance extended to longer lags in individuals with impaired reading ability (Buchholz \& Davies, 2007; Facoetti, Ruffino, Peru, Paganoni, \& Chelazzi, 2008; Hari et al., 1999; Lum et al., 2007; Visser et al., 2004). In one case, however, the opposite claim was made, such that individuals with dyslexia were said to have displayed a smaller $\mathrm{AB}$ effect than individuals without dyslexia (Lacroix et al., 2005). In only one of these investigations was an interaction between reading-ability group and lag reported (La Rocque \& Visser, 2009). The absence of differences in the lag-dependent effect on $\mathrm{T} 2$ performance between reading-ability groups indicates that the $\mathrm{AB}$ effect did not differ between the groups. What led these authors to claim that the $\mathrm{AB}$ effect differed between the reading-ability groups was a main effect of group on $\mathrm{T} 2$ performance, where overall $\mathrm{T} 2$ performance, averaged across lags, differed for the two groups. This main effect on T2 performance was observed both in the cases in which it was claimed that the $\mathrm{AB}$ effect was larger in individuals with impaired reading ability (Buchholz \& Davies, 2007; Facoetti et al., 2008; Hari et al., 1999; Lum et al., 2007; Visser et al., 2004) and in the one case in which the opposite claim was made (Lacroix et al., 2005).

A main effect of group indicates that T2 performance differed between the groups regardless of lag, and thus that the groups differed on T2 performance overall, not in a lagdependent manner that would define an AB effect. Differences in T2 performance overall would change the height of the lag-dependent effect on T2 performance, but the particular temporal pattern of the lag-dependent effect (i.e., the slope of the function; see Fig. 7) would not differ, such that the functions were additive. Certainly this indicates that the two groups differed in T2 performance, but it also indicates that the $\mathrm{AB}$ effect, that particular pattern of $\mathrm{T} 2$ performance according to lag, was equivalent between the two groups. Only one investigation of group differences in reading ability and the $\mathrm{AB}$ has correctly interpreted this main effect of 
Equivalent Modulations in T2 Performance Across all Lags Do Not Reflect a Modulation of the AB

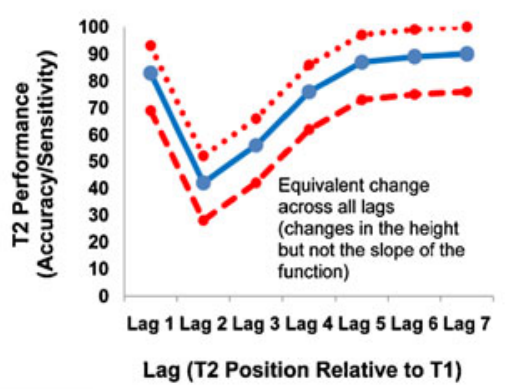

Fig. 7 A main effect of group or condition would correspond to differences in the height of the T2 function, not the slope

group as an effect on $\mathrm{T} 2$ performance, but not the $\mathrm{AB}$ (McLean et al., 2010). This is the misinterpretation, the confusion of slope height, discussed earlier.

Investigations of reading impairment are not the only area in which group differences in the $\mathrm{AB}$ have been claimed without the requisite interaction between group and lag. The same error in interpretation was also present, for example, in claims that schizophrenics displayed a larger $\mathrm{AB}$ effect (Cheung et al., 2002; Wynn et al., 2006) and in claims that children and adults with ADHD displayed a larger AB effect (Armstrong \& Munoz, 2003; Mason et al., 2005). Similarly, in these studies a main effect of group, indicating differences in $\mathrm{T} 2$ performance, led the authors to conclude that the $\mathrm{AB}$ differed between the groups. This same mistake in interpretation has been observed in experimental manipulations of the AB effect (e.g., Cooper et al., 2004).

This is not to say that group differences have never been observed in the AB. Several investigations have found the interaction with lag necessary to indicate that the $\mathrm{AB}$ effect differed between groups, such as videogame players and nonvideogame players (Green \& Bavelier, 2003); older and younger adults (van Leeuwen, Müller, \& Melloni, 2009); individuals with no, moderate, or severe dysphoria (Rokke, Arnell, Koch, \& Andrews, 2002); and Calvinists and atheists (Colzato, Hommel, \& Shapiro, 2010). As well, many experimental manipulations of the $\mathrm{AB}$ within subjects have also demonstrated the required interaction - for example, the many studies that have shown that some kinds of T2 stimuli can reduce the magnitude of the $\mathrm{AB}$, such as affectively arousing words (Keil \& Ihssen, 2004), smoking-related words in smokers (Waters, Heishman, Lerman, \& Pickworth, 2007), and alcohol-related words in alcoholics (Tibboel, De Houwer, \& Field, 2010). In all of these cases, lag interacted with the type of T2 stimulus used, such that the lagdependent effect differed according to the T2 stimulus type.

It is possible for groups or experimental conditions to demonstrate both a main effect and an interaction, such that the groups or conditions of interest differ both in overall $\mathrm{T} 2$ performance and in the $\mathrm{AB}$ effect, as was observed by, for example, both van Leeuwen et al. (2009) and La Rocque and
Visser (2009). However, the two effects are dissociable, such that a main effect of group can exist without an interaction with lag (as in the reading-ability literature reviewed above), and vice versa (e.g., Rokke et al., 2002).

While the interaction of group or condition with lag is necessary to indicate that the $\mathrm{AB}$ has been modulated, the nature of that interaction may lead to different degrees of certainty regarding the modulation of the $\mathrm{AB}$. This is because an interaction with the lag effect on $\mathrm{T} 2$ performance can result from various changes in the temporal pattern of $\mathrm{T} 2$ performance. Interactions that result from a T2 accuracy difference shown only during the critical short-lag period in which the posttarget impairment is present unambiguously reflect modulations of the AB. Interactions that result from a T2 accuracy difference at longer lags, outside of the critical period, do not exclude effects on the $\mathrm{AB}$, but they can be more difficult to interpret. Similarly, interactions that result from changes in T2 accuracy at lag 1 are also difficult to interpret. For example, it would be difficult to conclude that the $\mathrm{AB}$ was modulated if, when T2 accuracy at lag 1 was excluded, there were only a main effect of $\mathrm{T} 2$ performance and no interaction with lag.

The majority of investigations reviewed indicated that the interaction of the conditions or groups of interest with lag was due to differences between conditions or groups at shorter, but not at longer, lags (e.g., Akyürek, Hommel, \& Jolicœur, 2007; Arend, Johnston, \& Shapiro, 2007; Colzato, Slagter, Spapé, \& Hommel, 2008; Rokke et al., 2002; Shapiro et al. 1997b; Smith, Most, Newsome, \& Zald, 2006; Stein et al., 2009). This pattern provides a clear case for concluding that the $\mathrm{AB}$ effect, the posttarget impairment confined to a critical period, was modulated (see Fig. 8a). However, alternative patterns are also indicative of $A B$ effect modulations. For example, several investigations have demonstrated that the experimental conditions of interest resulted in a decrease in T2 performance at shorter lags, as well as an increase in T2 performance at longer lags (see Fig. 8b; Jolicœur, 1998; MacLean \& Arnell, 2011; Olson, Chun, \& Anderson, 2001). Similarly, in some cases T2 performance either increases or decreases at all lags in the same direction, yet the effect on T2 performance at shorter lags is greater than at longer lags (see Fig. 8c; Olivers \& Nieuwenhuis, 2005, 2006).

A more complicated case is when an interaction results from a difference between groups or conditions that is evident only at longer lags (see Fig. 9). Such an interaction may indicate that $\mathrm{T} 2$ performance within the critical period was unaffected by the group or manipulation of interest, suggesting that the $\mathrm{AB}$ was not modulated. However, it is possible that an experimental manipulation or group difference that affects only longer-lag T2 performance and not T2 performance during the critical period could have interesting implications for the $\mathrm{AB}$. It is also possible that the combination of a main effect on $\mathrm{T} 2$ performance and a particular interaction could make it appear (erroneously) that the 
Fig. 8 Three examples depicting interactions of condition or group with lag, such that the $A B$ effect is modulated

Modulations of T2 Performance That Unambiguously Reflect a Modulation of the $A B$
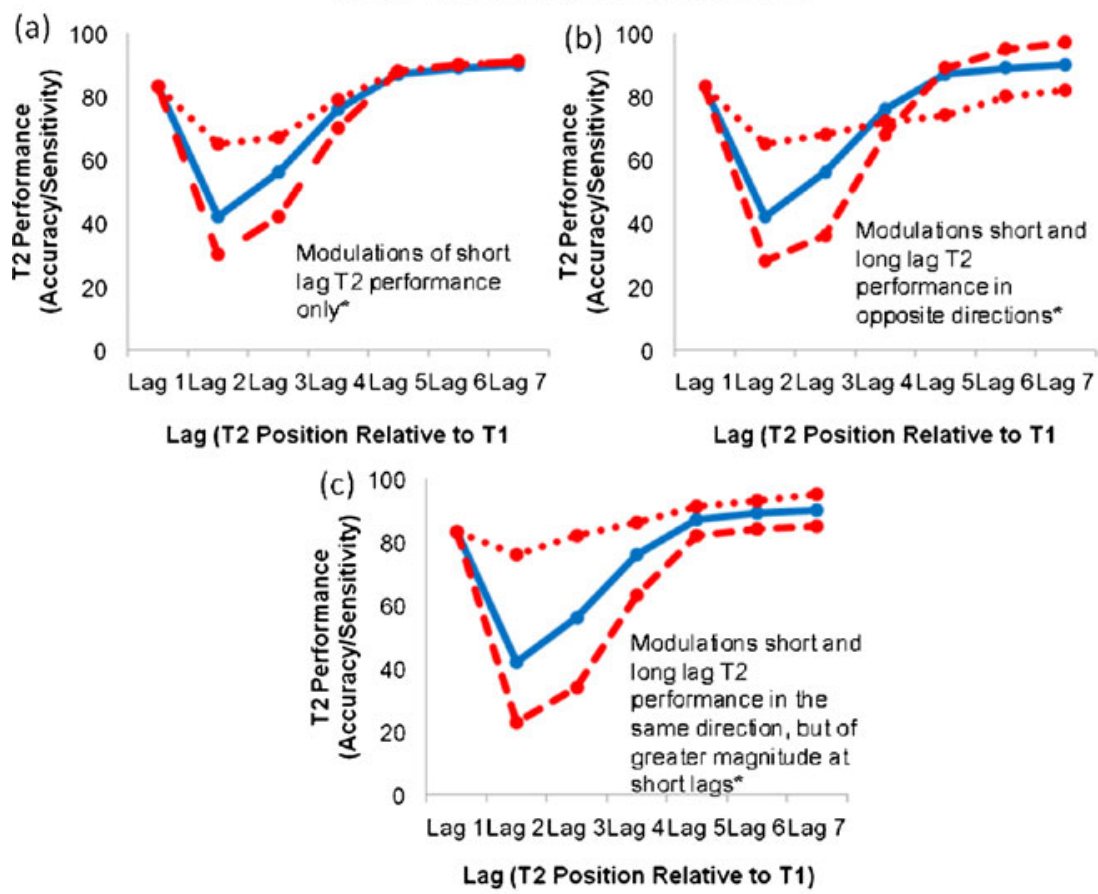

- Note that although not evident from these examples, modulations of the $A B$ are not exclusive of modulations of lag 1 sparing

manipulation is not active at shorter lags. For example, if a manipulation lowered T2 accuracy at shorter lags for Condition $\mathrm{A}$ but not for Condition $\mathrm{B}$, and this was combined with a main effect in which $\mathrm{T} 2$ accuracy was greater at all lags for Condition A than for Condition B, the interaction would appear as a difference only at the longer lags.

In summary, the $\mathrm{AB}$ effect is a lag-dependent effect on $\mathrm{T} 2$ performance with a particular temporal pattern, such that $\mathrm{T} 2$ performance increases from shorter to longer lags. The necessary, but not sufficient, evidence to indicate that an experimental manipulation modulates or that groups differ in the $\mathrm{AB}$ effect is the interaction of condition or group with the effect of lag on T2 performance. A main effect of condition or group is only indicative of an effect on $\mathrm{T} 2$ performance regardless of lag, and thus not of the $\mathrm{AB}$ effect. However, it is also necessary to perform sufficient follow-up to determine the nature of the interaction.

\section{Capturing individual differences in $\mathrm{AB}$ magnitude}

Researchers are sometimes interested in estimating the $\mathrm{AB}$ magnitude for a given individual. Evidence of reliable
Fig. 9 Two examples depicting interactions of condition or group with lag that are more difficult to interpret as modulations of the $\mathrm{AB}$

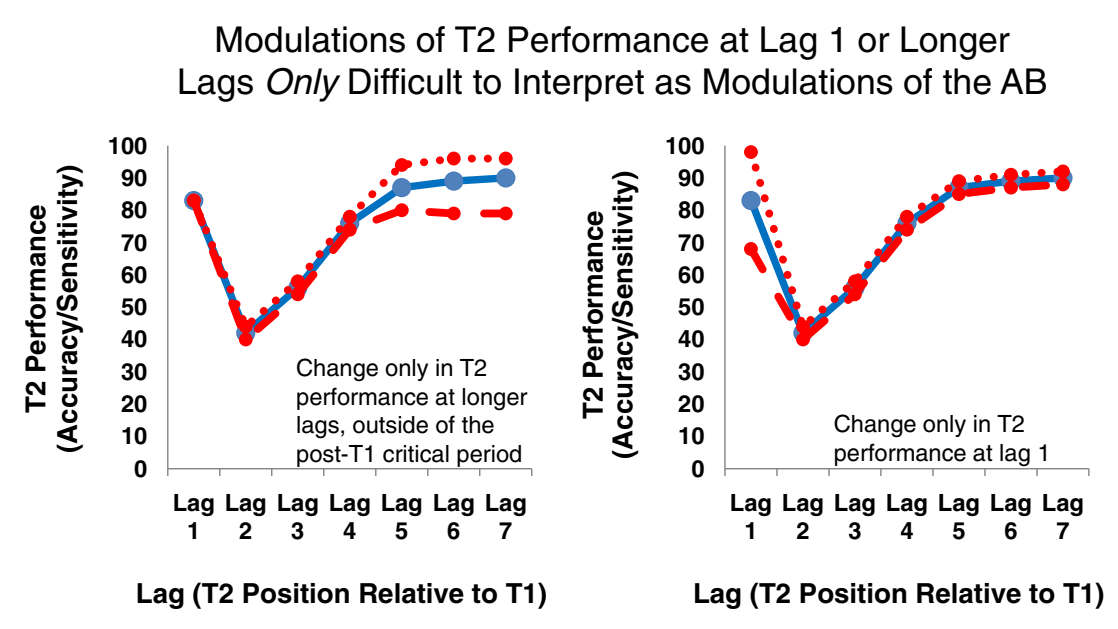


individual differences in the magnitude of the $\mathrm{AB}$ effect has been found (Dale \& Arnell, in press; McLaughlin et al., 2001). For example, McLaughlin et al. reported a correlation of .66 for two different $\mathrm{AB}$ tasks performed four weeks apart, and Dale and Arnell (in press) have shown good within-task and -session and cross-task and -session reliability using two different $\mathrm{AB}$ tasks. This has led some researchers to ask what measures can predict who will have a large or a small AB (e.g., Arnell et al., 2006; Martens et al., 2006). Various investigations have examined variables that could explain the interindividual variability in AB magnitude using a correlational approach. For example, personality (MacLean \& Arnell, 2010), affective traits (MacLean \& Arnell 2010), affective states (MacLean \& Arnell, 2010), religious behavior (Colzato et al., 2010), working memory control (Arnell et al., 2010; Colzato et al., 2007), reading ability (McLean, Stuart, Visser, \& Castles, 2009), global/local bias (Dale \& Arnell, 2010), resting EEG (MacLean, Arnell, \& Cote, 2012), and the ability to keep irrelevant material out of working memory (Arnell \& Stubitz, 2010; Dux \& Marois, 2009) have all been used to investigate individual differences in $\mathrm{AB}$ magnitude.

In order to investigate individual differences in the $\mathrm{AB}$ using a correlational approach, it is necessary to capture the magnitude of the $\mathrm{AB}$ effect for each individual as a single value. There are several possible methods for estimating $\mathrm{AB}$ magnitude within an individual. Many of the criteria necessary to accurately capture individual differences in the $\mathrm{AB}$ effect are related to those criteria relevant to testing for an $\mathrm{AB}$ and for modulations of the $\mathrm{AB}$, as discussed above. The primary requirement remains that in order to capture the $\mathrm{AB}$ effect, it is necessary to capture the lagdependent effect on T2 performance. Not all measures of T2 performance meet this criterion. For example, a recent investigation sought to examine individual differences in the $\mathrm{AB}$ in the context of various perceptual and cognitive performance measures (Klein et al., 2011). However, all of the correlations reported were of T2 performance at short lags or at long lags, without controlling for performance at the other lags. Thus, similar to the majority of investigations into reading ability and the $\mathrm{AB}$ (see above), Klein et al.'s investigation concerned T2 performance levels per se, not individual differences in the lag-dependent effect on $\mathrm{T} 2$ performance that is the hallmark of the $\mathrm{AB}$ effect. Furthermore, investigations into individual differences in the $\mathrm{AB}$ have demonstrated that overall $\mathrm{T} 2$ performance and the slope of the lag-dependent effect on T2 performance are qualitatively different. Specifically, some variables have been shown to predict the lag-dependent impairment that is the $\mathrm{AB}$, but not overall T2 performance. For example, individual differences in extraversion (MacLean \& Arnell, 2010) and global precedence (Dale \& Arnell, 2010) have been shown to predict AB magnitude but not overall T2 performance. Conversely, individual differences in fluid nonverbal intelligence and response times on various speeded tasks have been shown to predict overall T2 accuracy, but not AB magnitude (Arnell et al.,
2006; Arnell et al., 2010; Colzato et al., 2007). This suggests that interindividual variability in the height of the lagdependent function is dissociable from interindividual variability in the slope of the lag-dependent function (i.e., the $\mathrm{AB}$ ). This also emphasizes the importance of removing the confounding influence of the height of the lag-dependent function from estimates of individuals' $\mathrm{AB}$ magnitude.

As we discussed above, in order to accurately estimate the $\mathrm{AB}, \mathrm{T} 2$ performance must be examined at a minimum of two lags; one within the critical short-lag period in which the posttarget impairment is typically present, and one at a longer lag at which the posttarget impairment is typically absent. This is also the case when estimating an individual's $A B$ score for individual-difference studies of the $\mathrm{AB}$. However, this practice has not always been observed. For example, one investigation examined the relationship between the $\mathrm{AB}$ and prepulse inhibition magnitude in order to determine whether the two phenomena shared a common cognitive source (Cornwell, Echiverri, \& Grillon, 2006). The authors correlated T2 performance at lags 1 (SOA $117 \mathrm{~ms}$ ), 2 (SOA $234 \mathrm{~ms}$ ), and 3 (SOA $351 \mathrm{~ms}$ ) with prepulse inhibition magnitude, and found a significant positive relationships at lags 2 and 3 , but not at lag 1 . This is sufficient evidence to indicate that the correlations do not extend to lag-1 sparing, which the authors accurately indicated is not part of the $\mathrm{AB}$ effect. However, this is not sufficient evidence to indicate that prepulse inhibition magnitude correlates with $\mathrm{AB}$ magnitude: It is possible that similar correlations would have been observed with $\mathrm{T} 2$ performance at longer lags outside of the critical period as well. In that case, the magnitude of prepulse inhibition would have correlated positively with $\mathrm{T} 2$ performance, regardless of lag (i.e., with overall T2 performance, not with an $\mathrm{AB}$ effect). Without examining the correlations with T2 performance at longer lags, it is not possible to determine whether this was the case. By simply examining correlations with $\mathrm{T} 2$ performance at shorter lags in the context of T2 performance at longer lags, it would be possible to draw conclusions about individual differences in $\mathrm{AB}$ magnitude.

Methods are available to create a single numerical estimate that estimates the lag-dependent effect on T2 performance for an individual. One such approach is to subtract T2 performance at the shorter lags from $\mathrm{T} 2$ performance at longer lags (i.e., a difference score). Despite the fact that difference scores cannot be more reliable than the scores that are used to create the difference, several authors have successfully used this approach to predict individual differences in $\mathrm{AB}$ magnitude (Arnell et al., 2010; Arnell \& Stubitz, 2010; Colzato et al., 2007; Dale \& Arnell, 2010; MacLean \& Arnell, 2010; MacLean et al., 2010; Martens \& Johnson, 2009; McLean et al., 2009).

This difference score can be expected to estimate an individual's $\mathrm{AB}$ magnitude appropriately to the degree to which (1) an overall $\mathrm{AB}$ is observed in the grand mean, (2) appropriate lags are chosen to estimate short- and long-lag performance, (3) the short- and long-lag estimates are 
reliable estimates of T2 accuracy at those lags, (4) floor effects are avoided at the short lags and ceiling effect are avoided at the long lags (see Box 1), and (5) individuals differ in their T2 performance at short lags. Depending on the lags used for the short lag, this difference measure may be influenced both by the rate of recovery from the post-T1 impairment, where larger difference scores may reflect a slower rate of recovery and a longer AB duration (McLean et al., 2009), and by a short-lag T2 accuracy deficit relative to longer lags, where larger difference scores may reflect a deeper AB. Using a short lag within the critical period during which T2 performance is lowest (typically lag 2 or 3 ) to compute the difference score will reflect the depth of the $\mathrm{AB}$ effect. Using short lags still within the critical period, when $\mathrm{T} 2$ performance has begun to recover from the post-T1 impairment, will reflect both duration and depth. Lag 1 performance should generally not be used to compute a difference score meant to reflect $\mathrm{AB}$ magnitude, as it may be confounded with the effects of lag-1 sparing.

Box 1 . Issues with ceiling and floor effects in the $\mathrm{AB}$ paradigm

I

The presence of floor or ceiling effects may lead to reliable, but erroneous estimates of short or

I long lag accuracy given that it is impossible to distinguish individual differences in performance ability if

individual performance estimates are constrained by the floor or the ceiling (see figure below). Note also that

$\mathbf{I}$ this is similarly a problem when group performance is constrained by floor or ceiling, one possible consequence $\mathbf{I}$

I being that real additive effects (i.e. main effects) can appear as non-additive (i.e. interactions) and vice versa.

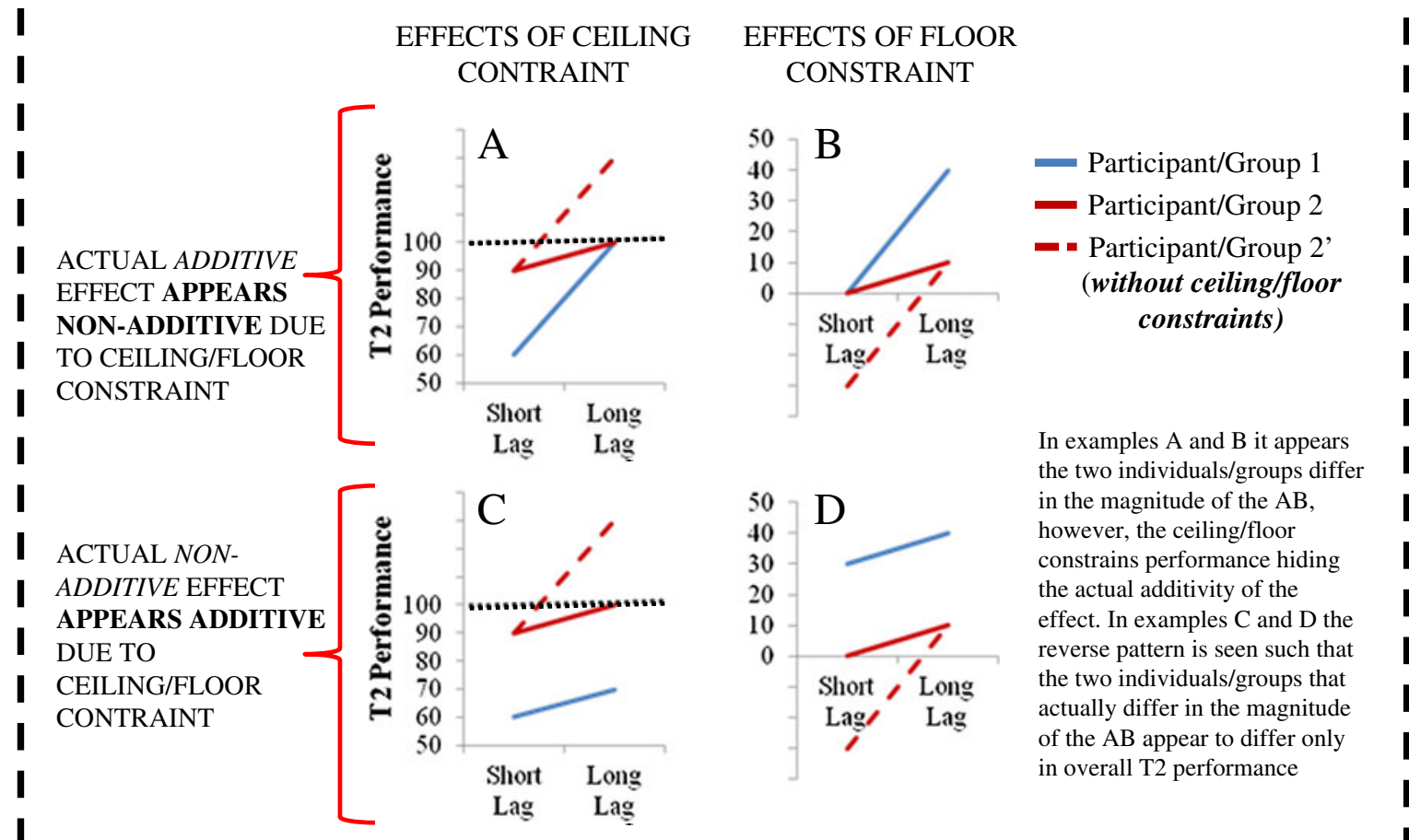

One approach recently used to avoid ceiling or floor constraints is to track individual thresholds for performance. For example, by dynamically manipulating the level of difficulty for the T2 task, or the I saliency of the T2 stimulus it is possible to measure individual differences in difficulty or saliency thresholds I I necessary to reach some pre-defined criteria. The $\mathrm{AB}$ would then be represented by the difference in the thresholds between shorter and longer lags. As the thresholds would be uniquely determined for each individual there would be no individual $\mathrm{AB}$ estimates confounded by ceiling or floor effects. Parameter Estimation by I Sequential Testing (PEST; Taylor \& Creelman, 1967) is an example of this type of approach that has been used I recently in the AB paradigm (Jannati, Spalek, \& Di Lollo, 2011).

Note that there is also more opportunity to show individual differences in the AB difference score if the T2 task is such that there is a lot of room between the floor and ceiling level performance. For I example, with a T2 task such as X versus Y discrimination, chance performance equals $50 \%$ and perfect $\mathbf{I}$ I performance equals 100\%, leaving a maximum 50\% range for the difference scores (less if you want to ensure avoidance of floor or ceiling effects). In contrast, for a task like "Which of the 26 letters was presented in red font?" chance performance approximates $4 \%$ and perfect performance equals $100 \%$, thereby leaving a I maximum 96\% range for the difference scores - a range that is likely to be more sensitive to individual I I differences in the $\mathrm{AB}$. 
There are variations of the difference measure-for example, using $\mathrm{T} 1$ performance instead of $\mathrm{T} 2$ performance at longer lags (Chua, 2005; Martens \& Johnson, 2009; McLaughlin et al., 2001) or taking the sum of the difference between $\mathrm{T} 2$ performance at each lag as compared to a control condition (Raymond et al., 1992) or to ceiling performance (100\%), also known as the area above the curve (Shapiro et al., 1994). A similar approach is to calculate a ratio rather than the difference-for example, $\mathrm{T} 2$ performance at a shorter lag divided by $\mathrm{T} 2$ performance at the longer lag and multiplied by 100 to yield a percentage (Tibboel et al., 2010).

The problem with any difference measure of $\mathrm{AB}$ magnitude is that it will be influenced by whatever baseline is used to create the difference. For example, individuals with the exact same $A B$ magnitude as measured by the difference could have very different levels of T2 performance at shorter and longer lags (e.g., an $\mathrm{AB}$ difference score of $40 \%$ could result from $60 \%$ long-lag T2 accuracy - $20 \%$ short-lag T2 accuracy or from $90 \%$ long-lag T2 accuracy $-50 \%$ short-lag T2 accuracy). Individual differences in long-lag T2 accuracy are potentially problematic, given that a participant with high long-lag T2 accuracy has more room to show a large AB than does an individual with lower long-lag T2 accuracy. For example, a participant who has $90 \%$ long-lag T2 accuracy could have a maximum $\mathrm{AB}$ difference score as large as $80 \%$ (i.e., $90 \%-10 \%$ ) on a ten-alternative forced choice task, in which chance is $10 \%$. In contrast, a participant who has $60 \%$ long-lag $\mathrm{T} 2$ accuracy could only have a maximum $\mathrm{AB}$ difference score of $50 \%$ (i.e., $60 \%-10 \%$ ) with the same task. Thus, it is desirable that any measure of $\mathrm{AB}$ magnitude not be confounded with baseline target performance.

One possible approach (used by Dux \& Marois, 2007) to reduce the influence of different baselines is to log-transform accuracy values, such that the data are rescaled in a manner that creates equivalent proportional and absolute effects for a manipulation such as lag (see Schweickert, 1985). Another solution that can be easily used to control for individual differences in overall T2 accuracy is to use multiple regression to separate the interindividual variability in the difference from the interindividual variability in overall $\mathrm{T} 2$ performance (i.e., to examine the lag-dependent decrease in $\mathrm{T} 2$ accuracy, controlling for individual differences in overall $\mathrm{T} 2$ accuracy). For example, McLean et al. (2009) included a measure of overall $\mathrm{T} 2$ performance, averaged across lags, in a regression with a difference measure of $\mathrm{AB}$ magnitude (i.e., $\mathrm{T} 2$ performance at long lag - T2 performance at short lag). This allowed them to attribute any correlation with the difference measure to variability in the lag-dependent effect on $\mathrm{T} 2$ performance over and above overall $\mathrm{T} 2$ performance. This method was also used to examine the relationship between $\mathrm{AB}$ magnitude and individual differences in the ability to keep irrelevant information out of visual working memory (Arnell \& Stubitz, 2010).
In addition to being concerned that the difference measure of $A B$ magnitude is accurate for all individuals and not confounded by individual differences in baseline performance, it is more generally a concern that interindividual variability in the difference measure of $\mathrm{AB}$ magnitude is a mixture composed of variability in $\mathrm{T} 2$ performance at shorter and at longer lags. The implicit assumption when reporting positive or negative correlations between individuals' scores on a predictor variable and the same individuals' scores on the $\mathrm{AB}$ measure is that the predictor variable predicted the magnitude of the post-T1 impairment while not being related to long-lag T2 performance. It is not possible, however, to determine whether correlations with the difference measure of $\mathrm{AB}$ magnitude alone reflect relationships with $\mathrm{T} 2$ performance at shorter lags during the critical period (i.e., the post-T1 impairment), long-lag T2 performance, or both. So, it is always possible that a correlation with a difference measure of $\mathrm{AB}$ magnitude may actually be driven by a correlation with long-lag $\mathrm{T} 2$ performance, not with T2 performance at short lags. Again, regression can be used to capture individual differences in the $\mathrm{AB}$ effect, but this time predicting $\mathrm{T} 2$ accuracy at short lags while controlling for T2 accuracy at long lags. This approach captures the lag-dependent effect on $\mathrm{T} 2$ performance (i.e., variability in $\mathrm{T} 2$ performance that is not shared across short and long lags), while at the same time controlling for variability in the baseline, and allowing one to test whether the predictor explains T2 performance at the short lag. The corresponding analysis can also be performed when longlag T2 accuracy is the criterion and short-lag T2 accuracy and the predictor of interest are both included as predictors. Thus, correlations could be examined using the interindividual variability that is unique to $\mathrm{T} 2$ performance at shorter and longer lags, independently (i.e., semipartial correlations).

For example, MacLean et al. (2010) showed that trait positive affect predicted increased T2 accuracy at short lags, and trait negative affect predicted decreased T2 accuracy at short lags, when controlling for T2 accuracy at long lags by using long-lag T2 accuracy as a simultaneous predictor. In contrast, when T2 accuracy at long lags was predicted, controlling for T2 accuracy at short lags, positive affect predicted decreased $\mathrm{T} 2$ accuracy, and negative affect predicted increased $\mathrm{T} 2$ accuracy. These analyses revealed that the pattern observed with the $\mathrm{AB}$ difference scores (decreased $\mathrm{AB}$ for positive affect and increased $A B$ for negative affect) resulted from affect modulating short- and long-lag T2 performance in opposite directions.

As a statistically equivalent alternative to multiple regression, it is also possible to save the residual variability from a regression (i.e., the variability in the criterion not accounted for by the predictors) as a new variable to use in a zero-order correlational approach. For example, saving the residuals from a regression with $\mathrm{T} 2$ performance at shorter lags as the criterion 
and T2 performance at longer lags as the predictor creates a new variable that captures short-lag T2 accuracy while controlling for $\mathrm{T} 2$ accuracy at long lags.

In summary, examining individual differences in $\mathrm{AB}$ magnitude, similar to experimental approaches to studying the $\mathrm{AB}$ effect, requires that the measure of individual differences in AB magnitude capture the lag-dependent effect on $\mathrm{T} 2$ performance. It is also important that the measure of $\mathrm{AB}$ magnitude not be confounded with individual differences in the baseline target performance. There are various solutions to this issue, including the use of multiple regression analyses.

\section{Examining neural correlates of the $\mathrm{AB}$}

Investigators may wish to examine correlates of the $\mathrm{AB}$ outside of the context of individual differences. For example, several studies have investigated neural correlates of the $\mathrm{AB}$ using various imaging techniques, such as MEG/EEG (Gross et al., 2004; MacLean \& Arnell, 2011; Sergent, Baillet, \& Dehaene, 2005; Shapiro, Schmitz, Martens, Hommel, \& Schnitzler, 2006) and fMRI (Kranczioch, Debener, Schwarzbach, Goebel, \& Engel, 2005; Marois, Yi, \& Chun, 2004). One way to examine correlates of the AB is to select trials post-hoc according to the performance outcomes on those trials and to examine differences in the particular correlate of interest between those trials with different performance outcomes. For example, MacLean and Arnell (2011) showed that alpha event-related desynchronization (ERD) was greater on short-lag trials in which T2 performance was incorrect than on short-lag trials in which T2 performance was correct, whereas the opposite pattern was true for T2 performance at long lags. Thus, alpha ERD was shown to be a correlate of the AB (MacLean \& Arnell, 2011). It is important to note that correlates such as alpha ERD are exactly that, correlated with the $\mathrm{AB}$; whether an $\mathrm{AB}$ was observed on a given trial is determined post-hoc and is not an experimentally manipulated variable. To be clear, this approach is therefore correlational, and differences in, for example, brain activity between $\mathrm{AB}$ and no- $\mathrm{AB}$ trials cannot be treated as the cause for the $\mathrm{AB}$ outcome.

It is also worth noting that it is not enough to examine patterns of activation for $\mathrm{T} 2$ correct and $\mathrm{T} 2$ incorrect trials at the short lags within the $\mathrm{AB}$ window, but that it is also necessary to examine $\mathrm{T} 2$ incorrect and $\mathrm{T} 2$ correct trials when $\mathrm{T} 2$ was presented at longer lags outside of the critical post-T1 period. Recall from the discussion above that both a short and a long lag are necessary to conclude that an $\mathrm{AB}$ has been modulated. If only a short lag is used, it is impossible to know whether the manipulation simply influences T2 accuracy overall or influences T2 accuracy in the lag-dependent manner that is the AB. Similarly, both a short and long lag are needed when attempting to examine correlates of the AB using the post-hoc trial selection approach. If both a short and a long lag are used, it is possible to determine whether differences in brain activity are found between $\mathrm{T} 2$ correct and $\mathrm{T} 2$ incorrect trials regardless of lag, or whether such differences are modulated by lag. For example, while alpha ERD was seen to be larger on T2 incorrect than on T2 correct trials at the short lag, the opposite pattern was observed at the long lag, indicating that the difference was dependent on lag, and thus was correlated with the $\mathrm{AB}$ and not simply with $\mathrm{T} 2$ performance (MacLean \& Arnell, 2011). Those studies that have examined neural correlates of $\mathrm{T} 2$ performance while disregarding the influence of lag (e.g., Gross et al., 2004; Marois et al., 2004; Sergent et al., 2005) confounded the AB with other factors affecting $\mathrm{T} 2$ performance.

\section{General conclusion}

The AB is a popular paradigm that shows the cost over time of attending to a target. These attention costs are reflected in the particular pattern of T2 accuracy across T1-T2 lags. The pattern consistently demonstrates that $\mathrm{T} 2$ performance is impaired when $\mathrm{T} 2$ is presented approximately two to four items after T1, but is unimpaired at longer lags, and often relatively unimpaired at lag 1. By adhering to the criteria outlined in this tutorial, investigators can make sound conclusions regarding the $\mathrm{AB}$ effect and the attentional processes that it reflects.

\section{Recommendations}

For researchers to reliably observe an $\mathrm{AB}$, an $\mathrm{AB}$ paradigm

- Should include both T1 and T2 masks.

- Should contain at least two lags: a short lag $(<500 \mathrm{~ms}$, not lag 1) and a long lag (>500 ms).

- Does not require a control condition.

In order to accurately conclude that you have observed an $\mathrm{AB}$,

- A lag-dependent effect on T2 performance is required in which performance is lower at short lag(s) than at longer lag(s). Ideally, this would be analyzed statistically by comparing T2 accuracy at the short lag to T2 accuracy at an appropriately long lag.

- Lag-1 sparing is neither necessary nor sufficient.

- If T2 accuracy at a long lag is not used as the baseline, the ideal baseline is an ignore-T1 or T1-absent control condition. However, these differences should be interpreted in the context of T2 accuracy at the long lag.

The presence of an $\mathrm{AB}$ should not be inferred using any of the following methods:

(1) examination of short-lag T2 performance alone.

(2) comparing short-lag T2 performance to $100 \%$. 
(3) comparing short-lag T2 accuracy to T2 performance at lag 1 .

(4) comparing short-lag T2 performance to T1 performance, if the T1 and T2 tasks differ.

(5) comparing short-lag T2 accuracy to any estimate without examination of similar differences for long-lag T2 accuracy.

In order to accurately conclude that there is a modulation of the $\mathrm{AB}$ across conditions or groups,

- An interaction of the experimental condition or group with lag, typically captured in a two-factor ANOVA, is required.

- This interaction should be observable without the inclusion of lag 1 and should not result from the presence of ceiling or floor effects.

- It is not valid to interpret a main effect of group or condition along with an additive pattern across lags (such that there is not a significant condition-by-lag interaction) as a modulation of the AB.

In order to obtain valid individual estimates of $\mathrm{AB}$ magnitude,

- The estimate should represent the change in T2 performance at short relative to long lags.

- Estimates of the change across lags can be accomplished by using a difference score (long-lag T2 accuracy - shortlag T2 accuracy), or by estimating T2 accuracy at short lags while controlling for $\mathrm{T} 2$ accuracy at long lags. If the latter method is performed, this should be accompanied by a separate estimate of T2 accuracy at long lags, controlling for T2 accuracy at short lags, with both estimates being related to the various predictor measures.

- Any measure of AB magnitude for an individual should not be confounded with individual differences in lag-1 sparing or baseline target performance, or be constrained by ceiling or floor performance.

\section{References}

Akyürek, E. G., \& Hommel, B. (2005). Target integration and the attentional blink. Acta Psychologica, 119, 305-314. doi:10.1016/ j.actpsy.2005.02.006

Akyürek, E. G., Hommel, B., \& Jolicœur, P. (2007). Direct evidence for a role of working memory in the attentional blink. Memory \& Cognition, 35, 621-627.

Arend, I., Johnston, S., \& Shapiro, K. (2007). Task-irrelevant visual motion and flicker attenuate the attentional blink. Psychonomic Bulletin \& Review, 13, 600-607. doi:10.3758/BF03193969

Armstrong, I. T., \& Munoz, D. P. (2003). Attentional blink in adults with attention-deficit hyperactivity disorder. Experimental Brain Research, 152, 243-250.

Arnell, K. M., Howe, A. E., Joanisse, M. F., \& Klein, R. M. (2006). Relationships between attentional blink magnitude, RSVP target accuracy, and performance on other cognitive tasks. Memory \& Cognition, 34, 1472-1483.

Arnell, K. M., \& Jenkins, R. (2004). Revisiting within-modality and cross-modality attentional blinks: Effects of target-distractor similarity. Perception \& Psychophysics, 66, 1147-1161.

Arnell, K. M., \& Jolicœur, P. (1999). The attentional blink across stimulus modalities: Evidence for central processing limitations. Journal of Experimental Psychology: Human Perception and Performance, 25, 630-648. doi:10.1037/0096-1523.25.3.630

Arnell, K. M., \& Larson, J. M. (2002). Cross-modality attentional blinks without preparatory task-set switching. Psychonomic Bulletin \& Review, 9, 497-506. doi:10.3758/BF03196305

Arnell, K. M., Stokes, K. A., MacLean, M. H., \& Gicante, C. (2010). Executive control processes of working memory predict attentional blink magnitude over and above storage capacity. Psychological Research, 74, 1-11. doi:10.1007/s00426-008-0200-4

Arnell, K. M., \& Stubitz, S. M. (2010). Attentional blink magnitude is predicted by the ability to keep irrelevant material out of working memory. Psychological Research, 74, 457-467.

Bowman, H., \& Wyble, B. (2007). The simultaneous type, serial token model of temporal attention and working memory. Psychological Review, 114, 38-70. doi:10.1037/0033-295X.114.1.38

Broadbent, D. E., \& Broadbent, M. H. P. (1987). From detection to identification: Response to multiple targets in rapid serial visual presentation. Perception \& Psychophysics, 42, 105113. doi: $10.3758 / \mathrm{BF} 03210498$

Buchholz, J., \& Davies, A. A. (2007). Attentional blink deficits observed in dyslexia depend on task demands. Vision Research, 47, 1292-1302. doi:10.1016/j.visres.2006.11.028

Cheung, V., Chen, E. Y. H., Chen, R. Y. L., Woo, M. F., \& Yee, B. K. (2002). A comparison between schizophrenia patients and healthy controls on the expression of attentional blink in a rapid serial visual presentation (RSVP) paradigm. Schizophrenia Bulletin, 28, 443-458.

Chua, F. K. (2005). The effect of target contrast on the attentional blink. Perception \& Psychophysics, 67, 770-788. doi:10.3758/ BF03193532

Chun, M. M., \& Potter, M. C. (2001). The attentional blink and taskswitching. In K. Shapiro (Ed.), Temporal constraints on human information processing (pp. 20-35). Oxford, U.K.: Oxford University Press.

Colzato, L. S., Hommel, B., \& Shapiro, K. (2010). Religion and the attentional blink: Depth of faith predicts depth of the blink. Frontiers in Psychology, 147, 1-7.

Colzato, L. S., Slagter, H. A., Spapé, M. M. A., \& Hommel, B. (2008). Blinks of the eye predict blinks of the mind. Neuropsychologia, 46, 3179-3183. doi:10.1016/j.neuropsychologia.2008.07.006

Colzato, L. S., Spapé, M. M. A., Pannebakker, M. M., \& Hommel, B. (2007). Working memory and the attentional blink: Blink size is predicted by individual differences in operation span. Psychonomic Bulletin \& Review, 14, 1051-1057. doi:10.3758/ BF03193090

Cooper, A. C. G., Humphreys, G. W., Hulleman, J., Praamstra, P., \& Georgeson, M. (2004). Transcranial magnetic stimulation to right parietal cortex modifies the attentional blink. Experimental Brain Research, 155, 24-29.

Cornwell, B. R., Echiverri, A. M., \& Grillon, C. (2006). Attentional blink and prepulse inhibition of startle are positively correlated. Psychophysiology, 43, 504-510.

Cousineau, D., Charbonneau, D., \& Jolicœur, P. (2006). Parameterizing the attentional blink effect. Canadian Journal of Experimental Psychology, 60, 175-189.

Craston, P., Wyble, B., \& Bowman, H. (2006). An EEG study of masking effects in RSVP. Journal of Vision, 6(6), $1016 \mathrm{a}$. doi:10.1167/6.6.1016

Dale, G., \& Arnell, K. M. (2010). Individual differences in dispositional focus of attention predict attentional blink magnitude. 
Attention, Perception, \& Psychophysics, 72, 602-606. doi:10.3758/APP.72.3.602

Dale, G., \& Arnell, K. M. (in press). How reliable is the attentional blink? Examining the relationships within and between attentional blink tasks over time. Psychological Research. doi:10.1007/ s00426-011-0403-y

Dell'Acqua, R., Jolicœur, P., Pascali, A., \& Pluchino, P. (2007). Shortterm consolidation of individual identities leads to lag-1 sparing. Journal of Experimental Psychology: Human Perception and Performance, 33, 593-609.

De Martino, B., Kalisch, R., Rees, G., \& Dolan, R. J. (2009). Enhanced processing of threat stimuli under limited attentional resources. Cerebral Cortex, 19, 127-133.

Di Lollo, V., Kawahara, J., Ghorashi, S. M. S., \& Enns, J. T. (2005). The attentional blink: Resource depletion or temporary loss of control? Psychological Research, 69, 191-200. doi:10.1007/ s00426-004-0173-x

Duncan, J., Martens, S., \& Ward, R. (1997). Restricted attentional capacity within but not between sensory modalities. Nature, 387, 808-810.

Duncan, J., Ward, R., \& Shapiro, K. (1994). Direct measurement of attentional dwell time in human vision. Nature, 369, 313-315.

Dux, P. E., Asplund, C. L., \& Marois, R. (2008). An attentional blink for sequentially presented targets: Evidence in favor of resource depletion accounts. Psychonomic Bulletin \& Review, 15, 809813. doi:10.3758/PBR.15.4.809

Dux, P. E., \& Marois, R. (2007). Repetition blindness is immune to the central bottleneck. Psychonomic Bulletin \& Review, 14, 729-734. doi:10.3758/BF03196829

Dux, P. E., \& Marois, R. (2009). The attentional blink: A review of data and theory. Attention, Perception, \& Psychophysics, 71, 1683-1700. doi:10.3758/APP.71.8.1683

Facoetti, A., Ruffino, M., Peru, A., Paganoni, P., \& Chelazzi, L. (2008). Sluggish engagement and disengagement of non-spatial attention in dyslexic children. Cortex, 44, 1221-1233.

Ferlazzo, F., Lucido, S., Di Nocera, F., Fagioli, S., \& Sdoia, S. (2007). Switching between goals mediates the attentional blink effect. Experimental Psychology, 54, 89-98. doi:10.1027/1618-3169.54.2.89

Folk, C. L., Leber, A. B., \& Egeth, H. E. (2008). Top-down control settings and the attentional blink: Evidence for non-spatial contingent capture. Visual Cognition, 16, 616-642.

Grandison, T. D., Ghirardelli, T. G., \& Egeth, H. E. (1997). Beyond similarity: Masking of the target is sufficient to cause the attentional blink. Perception \& Psychophysics, 59, 266-274.

Green, C. S., \& Bavelier, D. (2003). Action video game modifies visual selective attention. Nature, 423, 534-537. doi:10.1038/ nature 01647

Gross, J., Schmitz, F., Schnitzler, I., Kessler, K., Shapiro, K., Hommel, B., \& Schnitzler, A. (2004). Modulation of long-range neural synchrony reflects temporal limitations of visual attention in humans. Proceedings of the National Academy of Sciences, 35, 13050-13055.

Hari, R., Vata, M., \& Uutela, K. (1999). Prolonged attentional dwell time in dyslexic adults. Neuroscience Letters, 271, 202-204.

Ho, C., Mason, O., \& Spence, C. (2007). An investigation into the temporal dimension of the Mozart effect: Evidence from the attentional blink task. Acta Psychologica, 125, 117-128.

Hommel, B., \& Akyürek, E. G. (2005). Lag-1 sparing in the attentional blink: Benefits and costs of integrating two events into a single episode. Quarterly Journal of Experimental Psychology, 58A, 1415-1433. doi:10.1080/02724980443000647

Husain, M., Shapiro, K., Martin, J., \& Kennard, C. (1997). Abnormal temporal dynamics of visual attention in spatial neglect patients. Nature, 385, 154-156.

Jannati, A., Spalek, T. M., \& Di Lollo, V. (2011). Neither backward masking of T2 nor task switching is necessary for the attentional blink. Psychonomic Bulletin \& Review, 18, 70-75. doi:10.3758/ s13423-010-0015-3

Jolicœur, P. (1998). Modulation of the attentional blink by on-line response selection: Evidence from speeded and unspeeded Task ${ }_{1}$ decisions. Memory \& Cognition, 26, 1014-1032. doi:10.3758/ BF03201180

Jolicœur, P. (1999). Restricted attentional capacity between sensory modalities. Psychonomic Bulletin \& Review, 6, 87-92. doi:10.3758/ BF03210813

Jolicœur, P., \& Dell'Acqua, R. (1998). The demonstration of short-term consolidation. Cognitive Psychology, 36, 138-202. doi:10.1006/ cogp.1998.0684

Kawahara, J., Enns, J. T., \& Di Lollo, V. (2006a). The attentional blink is not a unitary phenomenon. Psychological Research, 70, 405413. doi:10.1007/s00426-005-0007-5

Kawahara, J., Kumada, T., \& Di Lollo, V. (2006b). The attentional blink is governed by a temporary loss of control. Psychonomic Bulletin \& Review, 13, 886-890. doi:10.3758/BF03194014

Keil, A., \& Ihssen, N. (2004). Identification facilitation for emotionally arousing verbs during the attentional blink. Emotion, 4, 23-35.

Kessler, K., Schmitz, F., Gross, J., Hommel, B., Shapiro, K., \& Schnitzler, A. (2005). Cortical mechanisms of attention in time: Neural correlates of the lag-1 sparing phenomenon. European Journal of Neuroscience, 21, 2563-2574.

Kihara, K., Hirose, N., Mima, T., Abe, M., Fukuyama, H., \& Osaka, N. (2007). The role of left and right intraparietal sulcus in the attentional blink: A transcranial magnetic stimulation study. Experimental Brain Research, 178, 135-140.

Klein, C., Arend, I. C., Beauducel, A., \& Shapiro, K. L. (2011). Individuals differ in the attentional blink: Mental speed and intra-subject stability matter. Intelligence, 39, 27-35.

Kranczioch, C., Debener, S., Schwarzbach, J., Goebel, R., \& Engel, A. K. (2005). Neural correlates of conscious perception in the attentional blink. NeuroImage, 24, 704-714. doi:10.1016/ j.neuroimage.2004.09.024

Lacroix, G. L., Constantinescu, I., Cousineau, D., de Almeida, R. G., Segalowitz, N., \& von Grünau, M. (2005). Attentional blink differences between adolescent dyslexic and normal readers. Brain and Cognition, 57, 115-119.

La Rocque, C. L., \& Visser, T. A. W. (2009). Sequential object recognition deficits in normal readers. Vision Research, 49, 96 101. doi:10.1016/j.visres.2008.09.027

Livesey, E. J., \& Harris, I. M. (2011). Target sparing effects in the attentional blink depend on type of stimulus. Attention, Perception, \& Psychophysics, 73, 2104-2123. doi:10.3758/s13414-011-0177-8

Lum, J. A. G., Conti-Ramsden, G., \& Lindell, A. K. (2007). The attentional blink reveals sluggish attentional shifting in adolescents with special language impairment. Brain \& Cognition, 63, 287-295.

MacLean, M. H., \& Arnell, K. M. (2010). Personality predicts temporal attention costs in the attentional blink paradigm. Psychonomic Bulletin \& Review, 17, 556-562. doi:10.3758/PBR.17.4.556

MacLean, M. H., \& Arnell, K. M. (2011). Greater attentional blink magnitude is associated with higher levels of anticipatory attention as measured by alpha event-related desynchronization (ERD). Brain Research, 1387, 99-107. doi:10.1016/ j.brainres.2011.02.069

MacLean, M. H., Arnell, K. M., \& Busseri, M. A. (2010). Dispositional affect predicts temporal attention costs in the attentional blink paradigm. Cognition and Emotion, 24, 1431-1438.

MacLean, M. H., Arnell, K. M., \& Cote, K. A. (2012). Resting EEG in alpha and beta bands predicts individual differences in attentional blink magnitude. Brain and Cognition, 78, 218-229. doi:10.1016/ j.bandc.2011.12.010

Maki, W. S., \& Padmanabhan, G. (1994). Transient suppression of processing during rapid serial visual presentation: Acquired 
distinctiveness of probes modulates the attentional blink. Psychonomic Bulletin \& Review, 1, 499-504. doi:10.3758/BF03210954

Marois, R., Yi, D.-J., \& Chun, M. M. (2004). The neural fate of consciously perceived and missed events in the attentional blink. Neuron, 41, 465-472.

Martens, S., \& Johnson, A. (2009). Timing attention: Cuing target onset interval attenuates the attentional blink. Memory \& Cognition, 33, 234-240.

Martens, S., \& Wyble, B. (2010). The attentional blink: Past, present, and future of a blind spot in perceptual awareness. Neuroscience and Biobehavioral Reviews, 34, 947-957.

Martens, S., Munneke, J., Smid, H., \& Johnson, A. (2006). Quick minds don't blink: Electrophysiological correlates of individual differences in attentional selection. Journal of Cognitive Neuroscience, 18, 1423-1438

Martin, E. W., \& Shapiro, K. L. (2008). Does failure to mask T1 cause lag-1 sparing in the attentional blink? Perception \& Psychophysics, 70, 562-570. doi:10.3758/PP.70.3.562

Mason, D. J., Humphreys, G. W., \& Kent, L. (2005). Insights into the control of attentional set in ADHD using the attentional blink paradigm. Journal of Child Psychology and Psychiatry, 46, 1345-1353.

McLaughlin, E. N., Shore, D. I., \& Klein, R. M. (2001). The attentional blink is immune to masking-induced data limits. Quarterly Journal of Experimental Psychology, 54A, 169-196. doi:10.1080/ 02724980042000075

McLean, G. M. T., Castles, A., Coltheart, V., \& Stuart, G. W. (2010). No evidence for a prolonged attentional blink in developmental dyslexia. Cortex, 46, 1317-1329.

McLean, G. M. T., Stuart, G. W., Visser, T. A. W., \& Castles, A. (2009). The attentional blink in developing readers. Scientific Studies of Reading, 13, 334-357.

Mondor, T. A. (1998). A transient processing deficit following selection of an auditory target. Psychonomic Bulletin \& Review, 5, 305-311. doi:10.3758/BF03212956

Munafò, M. R., Johnstone, E. C., \& Mackintosh, B. (2005). Association of serotonin transporter genotype with selective processing smoking-related stimuli in current and ex-smokers. Nicotine \& Tobacco Research, 7, 773-778.

Nieuwenstein, M. R., Potter, M. C., \& Theeuwes, J. (2009a). Unmasking the attentional blink. Journal of Experimental Psychology: Human Perception and Performance, 35, 159-169. doi:10.1037/ 0096-1523.35.1.159

Nieuwenstein, M., Van der Burg, E., Theeuwes, J., Wyble, B., \& Potter, M. (2009b). Temporal constraints on conscious vision: On the ubiquitous nature of the attentional blink. Journal of Vision, 9(9), 18), 1-14. doi:10.1167/9.9.18

Olivers, C. N. L., \& Meeter, M. (2008). A boost and bounce theory of temporal attention. Psychological Review, 115, 836-863. doi:10.1037/a0013395

Olivers, C. N. L., \& Nieuwenhuis, S. (2005). The beneficial effect of concurrent task-irrelevant mental activity on temporal attention. Psychological Science, 16, 265-269. doi:10.1111/j.09567976.2005.01526.x

Olivers, C. N. L., \& Nieuwenhuis, S. (2006). The beneficial effects of additional task load, positive affect, and instruction on the attentional blink. Journal of Experimental Psychology: Human Perception and Performance, 32, 364-379. doi:10.1037/0096-1523.32.2.364

Olivers, C. N. L., van der Stigchel, S., \& Hulleman, J. (2007). Spreading the sparing: Against a limited-capacity account of the attentional blink. Psychological Research, 71, 126-139. doi:10.1007/ s00426-005-0029-z

Olson, I. R., Chun, M. M., \& Anderson, A. K. (2001). Effects of phonological length on the attentional blink for words. Journal of Experimental Psychology: Human Perception and Performance, 27, 1116-1123.
Potter, M. C., Chun, M. M., Banks, B. S., \& Muckenhoupt, M. (1998). Two attentional deficits in serial target search: The visual attentional blink and an amodal task-switch deficit. Journal of Experimental Psychology: Learning, Memory, and Cognition, 24, 979-992.

Raymond, J. E. (2003). New objects, not new features, trigger the attentional blink. Psychological Science, 14, 54-59.

Raymond, J. E., \& O’Brian, J. L. (2009). Selective visual attention and motivation: The consequences of value learning in an attentional blink task. Psychological Science, 20, 981-988.

Raymond, J. E., Shapiro, K. L., \& Arnell, K. M. (1992). Temporary suppression of visual processing in an RSVP task: An attentional blink? Journal of Experimental Psychology: Human Perception and Performance, 18, 849-860. doi:10.1037/0096-1523.18.3.849

Raymond, J. E., Shapiro, K. L., \& Arnell, K. M. (1995). Similarity determines the attentional blink. Journal of Experimental Psychology: Human Perception and Performance, 21, 653-662.

Rokke, P. D., Arnell, K. M., Koch, M. D., \& Andrews, J. T. (2002). Dual-task attention deficits in dysphoric mood. Journal of Abnormal Psychology, 111, 370-379.

Schweickert, R. (1985). Separable effects of factors on speed and accuracy: Memory scanning, lexical decision, and choice tasks. Psychological Bulletin, 97, 530-546.

Seiffert, A. E., \& Di Lollo, V. (1997). Low-level masking in the attentional blink. Journal of Experimental Psychology: Human Perception and Performance, 23, 1061-1073. doi:10.1037/00961523.23.4.1061

Sergent, C., Baillet, S., \& Dehaene, S. (2005). Timing of the brain events underlying access to consciousness during the attentional blink. Nature Neuroscience, 8, 1391-1400.

Shapiro, K. L., Arnell, K. M., \& Raymond, J. E. (1997a). The attentional blink. Trends in Cognitive Sciences, 1, 291-296. doi:10.1016/S1364-6613(97)01094-2

Shapiro, K. L., Caldwell, J., \& Sorensen, R. E. (1997b). Personal names and the attentional blink: A visual "cocktail party" effect. Journal of Experimental Psychology: Human Perception and Performance, 23, 504-514. doi:10.1037/0096-1523.23.2.504

Shapiro, K. L., Raymond, J. E., \& Arnell, K. M. (1994). Attention to visual pattern information produces in attentional blink in rapid serial visual presentation. Journal of Experimental Psychology: Human Perception and Performance, 20, 357-371. doi:10.1037/ 0096-1523.20.2.357

Shapiro, K., Schmitz, F., Martens, S., Hommel, B., \& Schnitzler, A. (2006). Resource sharing in the attentional blink. NeuroReport, 17, 163-166.

Shen, D., \& Mondor, T. A. (2006). Effect of distractor sounds on the auditory attentional blink. Perception \& Psychophysics, 68, 228243. doi:10.3758/BF03193672

Shepard, R. N., \& Cooper, L. A. (1982). Mental images and their transformations. Cambridge, MA: MIT Press.

Shepard, R. N., \& Metzler, J. (1971). Mental rotation of threedimensional objects. Science, 171, 701-703. doi:10.1126/ science.171.3972.701

Shore, D. I., McLaughlin, E. N., \& Klein, R. M. (2001). Modulation of the attentional blink by differential resource allocation. Canadian Journal of Experimental Psychology, 55, 318-324. doi:10.1037/ h0087379

Smith, S. D., Most, S. B., Newsome, L. A., \& Zald, D. H. (2006). An emotion-induced attentional blink elicited by aversively conditioned stimuli. Emotion, 6, 523-527.

Soto-Faraco, S., Spence, C., Fairbank, K., Kingstone, A., Hillstrom, A. P., \& Shapiro, K. (2002). A crossmodal attentional blink between vision and touch. Psychonomic Bulletin Review, 9, 731-738.

Stein, T., Zwickel, J., Ritter, J., Kitzmantel, M., \& Schneider, W. X. (2009). The effect of fearful faces on the attentional blink is task dependent. Psychonomic Bulletin \& Review, 16, 104-109. doi:10.3758/PBR.16.1.104 
Taylor, M. M., \& Creelman, C. D. (1967). PEST: Efficient estimates on probability functions. Journal of the Acoustical Society of America, $41,782-787$.

Tibboel, H., De Houwer, J., \& Field, M. (2010). Reduced attentional blink for alcohol-related stimuli in heavy social drinkers. Journal of Psychopharmacology, 24, 1349-1356.

Treisman, A. M., \& Gelade, G. (1980). A feature-integration theory of attention. Cognitive Psychology, 12, 97-136. doi:10.1016/00100285(80)90005-5

Tremblay, S., Vachon, F., \& Jones, D. M. (2005). Attentional and perceptual sources of the auditory attentional blink. Perception \& Psychophysics, 67, 195-208. doi:10.3758/BF03206484

Trippe, R. H., Hewig, J., Heydel, C., Hecht, H., \& Miltner, W. H. R. (2007). Attentional blink to emotional and threatening pictures in spider phobics: Electrophysiology and behavior. Brain Research, $1148,149-160$.

Vachon, F., \& Tremblay, S. (2008). Modality-specific and amodal sources of interference in the attentional blink. Perception \& Psychophysics, 70, 1000-1015. doi:10.3758/PP.70.6.1000

van Leeuwen, S., Müller, N. G., \& Melloni, L. (2009). Age effects on attentional blink performance in meditation. Consciousness and Cognition, 18, 593-599.

Vermeulen, N., Godefroid, J., \& Mermillod, M. (2009). Emotional modulation of attention: Fear increases but disgust reduces the attentional blink. PLoS ONE, 4, e7924.

Visser, T. A. W., Bischof, W. F., \& Di Lollo, V. (1999a). Attentional switching in spatial and nonspatial domains: Evidence from the attentional blink. Psychological Bulletin, 125, 458-469. doi:10.1037/0033-2909.125.4.458
Visser, T. A. W., Boden, C., \& Giaschi, D. E. (2004). Children with dyslexia: Evidence for visual attention deficits in perception of rapid sequences of objects. Vision Research, 44, 2521-2535.

Visser, T. A. W., Davis, C., \& Ohan, J. L. (2009). When similarity leads to sparing: Probing mechanisms underlying the attentional blink. Psychological Research, 73, 327-335.

Visser, T. A. W., \& Ohan, J. L. (2007). Data-limited manipulations of T1 difficulty modulate the attentional blink. Canadian Journal of Experimental Psychology, 61, 102-108.

Visser, T. A. W., Zuvic, S. M., Bischof, W. F., \& Di Lollo, V. (1999b). The attentional blink with targets in different spatial locations. Psychonomic Bulletin \& Review, 6, 432-436. doi:10.3758/ BF03210831

Ward, R., Duncan, J., \& Shapiro, K. (1996). The slow time-course of visual attention. Cognitive Psychology, 30, 79-109.

Ward, R., Duncan, J., \& Shapiro, K. (1997). Effect of similarity, difficulty, and nontarget presentation on the time course of visual attention. Perception \& Psychophysics, 59, 593-600.

Waters, A. J., Heishman, S. J., Lerman, C., \& Pickworth, W. (2007). Enhanced identification of smoking-related words during the attentional blink in smokers. Addictive Behaviors, 32, 3077-3082.

Wolfe, J. M. (1998a). Visual search. In H. Pashler (Ed.), Attention (pp. 13-73). Hove, U.K.: Psychology Press.

Wolfe, J. M. (1998b). What can 1 million trials tell us about visual search? Psychological Science, 9, 33-39. doi:10.1111/1467-9280.00006

Wynn, J. K., Breitmeyer, B., Nuechterlein, K. H., \& Green, M. F. (2006). Exploring the short term visual store in schizophrenia using the attentional blink. Journal of Psychiatric Research, 40, 599-605. 